\title{
The Extreme UV Imager of Solar Orbiter - From detailed design to Flight Model
}

\author{
J.-P. Halain ${ }^{a^{*}}$, P. Rochus ${ }^{a}$, E. Renotte ${ }^{a}$, F. Auchère ${ }^{b}$, D. Berghmans ${ }^{g}$, L. Harra ${ }^{e}$, U. Schühle $^{d}$, W.

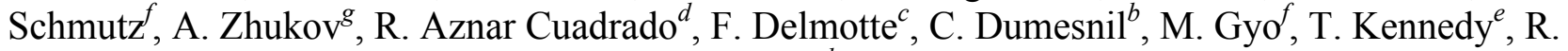

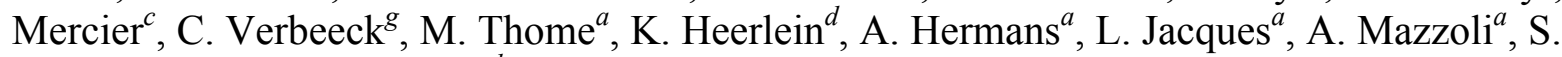

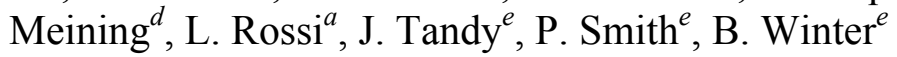 \\ ${ }^{a}$ Centre Spatial de Liège, Université de Liège, Liege Science Park, 4013 Angleur, Belgium \\ ${ }^{b}$ Institut d'Astrophysique Spatiale, Orsay, France \\ ${ }^{c}$ Institut d'optique, Orsay, France \\ ${ }^{\mathrm{d}}$ Max-Planck-Institut für Sonnensystemforschung, Göttingen, Germany \\ ${ }^{\mathrm{e}}$ Mullard Space Science Laboratory, Surrey, UK \\ ${ }^{\mathrm{f}}$ Physikalisch-Meteorologisches Observatorium Davos and World Radiation Center, Switzerland \\ ${ }^{\mathrm{g}}$ Royal Observatory of Belgium, Avenue Circulaire, Uccle, Belgium
}

\begin{abstract}
The Extreme Ultraviolet Imager (EUI) on-board the Solar Orbiter mission will provide full-sun and high-resolution image sequences of the solar atmosphere at selected spectral emission lines in the extreme and vacuum ultraviolet.

After the breadboarding and prototyping activities that focused on key technologies, the EUI project has completed the design phase and has started the final manufacturing of the instrument and its validation.

The EUI instrument has successfully passed its Critical Design Review (CDR). The process validated the detailed design of the Optical Bench unit and of its sub-units (entrance baffles, doors, mirrors, camera, and filter wheel mechanisms), and of the Electronic Box unit. In the same timeframe, the Structural and Thermal Model (STM) test campaign of the two units have been achieved, and allowed to correlate the associated mathematical models.

The lessons learned from STM and the detailed design served as input to release the manufacturing of the Qualification Model (QM) and of the Flight Model (FM).

The QM will serve to qualify the instrument units and sub-units, in advance of the FM acceptance tests and final onground calibration.
\end{abstract}

Keywords: Extreme Ultraviolet Imager, Lyman-alpha, Solar Orbiter, telescope, baffle, door mechanism, metal filter, multilayer coating, CMOS-APS camera

\section{INTRODUCTION}

The ESA Solar Orbiter mission ${ }^{[1],[2],[3]}$ is devoted to the solar observation from an elliptical orbit around the Sun approaching to $0.28 \mathrm{AU}$ with unprecedented close-up and high-latitude vantage point of views.

The Extreme Ultraviolet Imager (EUI) instrument is one of the ten scientific instruments of the Solar Orbiter mission ${ }^{[15]}$ that will provide images of the solar atmospheric layers from the chromosphere into the corona. Three channels are designed to image the Sun at selected wavelength and appropriate resolution to meet the science objectives:

- A High Resolution Imager (100 km resolution) at the hydrogen Lyman- $\alpha \operatorname{line}^{[12]}\left(\mathrm{HRI}_{\mathrm{Lya}}\right.$ channel),

- A High Resolution Imager (100 km resolution) at the extreme ultra-violet (EUV) $174 \AA$ line (HRI $\mathrm{EUV}_{\mathrm{EV}}$ channel),

- A Full Sun Imager (900 km resolution) at alternatively the EUV $174 \AA$ And $304 \AA ̊$ lines ${ }^{[7],[8]}$ (FSI channel).

EUI is a two-unit instrument based on a passive thermo-mechanical design (Figure 1). The Optical Bench System (OBS) unit holds the three telescope channels with mirrors, cameras, filter wheels, filters and doors mechanisms sub-systems ${ }^{[9]}$. 
The Common Electrical Box (CEB) unit operates the instrument and provides the data handling (processing and compression) of the three channels. It also provides the electrical interfaces with the spacecraft ${ }^{[9]}$.

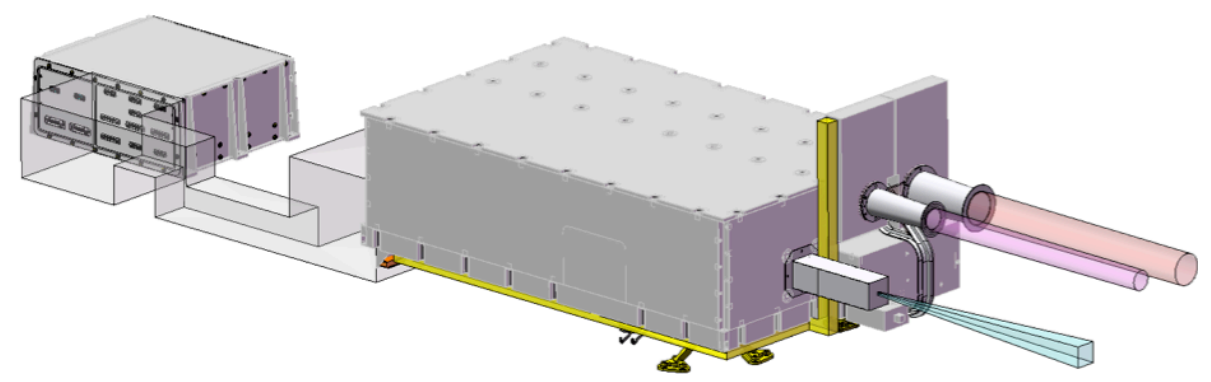

Figure 1 - The two units of EUI: CEB (left) and OBS (right), here shown with the interconnecting harness volume

After the development phase with the associated breadboarding and prototyping activities mostly oriented on key technologies and critical sub-systems ${ }^{[13]}$, the EUI project has completed its detailed design phase with the Instrument Critical Design Review (ICDR) and the Critical Design Review (CDR) of the sub-systems. In the same timeframe, the Structural and Thermal Model (STM) test campaign of the two units has been completed, and allowed to correlate the associated thermal and mechanical mathematical models

In the present paper, we summarize the detailed design of the EUI instrument and the lessons learned from the STM Assembly, Integration and Test (AIT) sequence. The objectives of the Engineering Model (EM) and of the Qualification Model (QM) that will follow the STM, in advance of the Flight Model (FM) are then presented.

\section{INSTRUMENT DETAILED DESIGN}

The EUI instrument had been previously described ${ }^{[9][13]}$, but its design has been further advanced in order to reach a sufficient detailed level for manufacturing. The present section summarizes the EUI design at CDR stage.

\subsection{Science performances}

The EUI high level science performances are summarized in Table 1.

Table 1 - EUI science performances

\begin{tabular}{|c|c|c|c|}
\hline & Parameter & Baseline & Comment \\
\hline \multirow{8}{*}{$\bar{\nabla}$} & Passband center & $17.4 \mathrm{~nm}$ and $30.4 \mathrm{~nm}$ & Million degree corona, Transition Region \\
\hline & Spectral purity & $>80 \%(30.4 \mathrm{~nm}),>90 \%(17.4 \mathrm{~nm})$ & \\
\hline & Filter band selection & $\mathrm{T}_{17.4} / \mathrm{T}_{30.4}>10^{4}, \mathrm{~T}_{30.4} / \mathrm{T}_{17.4}>10^{3}$ & \\
\hline & Field of View & $3.8 \operatorname{arcdeg} \times 3.8 \operatorname{arcdeg}$ & 4 solar radii at $0.28 \mathrm{~A} . \mathrm{U}$ \\
\hline & Angular resolution & $9 \operatorname{arcsec}$ & 2 px resolution \\
\hline & SNR & $>10$ & Below 1.2 solar radius \\
\hline & Dynamic range & Contrast $>10^{3} \mathrm{ph}$ & Min: $2 \mathrm{ph} /$ pixel, Max: $10^{4} \mathrm{ph} /$ pixel \\
\hline & Exposure time & $1 \mathrm{~s}$ to $1200 \mathrm{~s}$ & Cadence $>30 \mathrm{~s}$ \\
\hline \multirow{7}{*}{$\underset{\underline{\underline{x}}}{\underline{\underline{x}}}$} & Passband center & $17.4 \mathrm{~nm}$ & Million degree corona \\
\hline & Spectral purity & $>90 \%$ & \\
\hline & Field of View & 0.283 arcdeg & \\
\hline & Angular resolution & $1 \operatorname{arcsec}$ & 2 px resolution \\
\hline & SNR & $>10$ & In Quiet Sun regions \\
\hline & Dynamic range & Contrast $>10^{3} \mathrm{ph}$ & Min: $2 \mathrm{ph} /$ pixel, Max: $10^{4} \mathrm{ph} /$ pixel \\
\hline & Exposure time & $0.1 \mathrm{~s}$ to $1200 \mathrm{~s}$ & Cadence $>0.1 \mathrm{~s}$ \\
\hline \multirow{6}{*}{$\stackrel{\widetilde{s}}{\stackrel{3}{\Xi}}$} & Passband center & $121.6 \mathrm{~nm}$ & Transition region \\
\hline & Spectral purity & $>90 \%$ & \\
\hline & Field of View & 0.283 arcdeg & \\
\hline & Angular resolution & $1 \operatorname{arcsec}$ & 2 px resolution \\
\hline & SNR & $>10$ & In Quiet Sun regions \\
\hline & Dynamic range & Contrast $>10^{3} \mathrm{ph}$ & Min: $2 \mathrm{ph} /$ pixel, Max: $10^{4} \mathrm{ph} /$ pixel \\
\hline
\end{tabular}




\begin{tabular}{|l|l|l|l|}
\hline & Exposure time & $0.1 \mathrm{~s}$ to $1200 \mathrm{~s}$ & Cadence $>0.1 \mathrm{~s}$ \\
\hline \multirow{2}{*}{} & Photometric accuracy & $10 \%$ & \\
\cline { 2 - 4 } & Stray light level & $>90 \%$ PSF energy in px \\
$<1 \mathrm{DN}$ scattered and ghost & $\begin{array}{l}\text { Point Spread Function (PSF) at operational wavelength } \\
\text { Scattered and ghosts integrated from EUV to VIS }\end{array}$ \\
\hline & Min filter transmission & $\mathrm{T}_{17.4}>30 \%, \mathrm{~T}_{30.4}>30 \% \mathrm{~T}_{121.6}>30 \%$ & Visible transmission $<10^{-8}$ \\
\hline & Simultaneity & $<0.1 \mathrm{~s}$ & \\
\cline { 2 - 4 } & Co-alignment & $<1$ arcmin & 10 arcsec on the co-alignment knowledge. \\
\hline
\end{tabular}

\subsection{OBS unit}

The OBS unit structural housing is composed of sandwich panels (CFRP -Carbon Fibre Reinforced Polymer- facesheets / Aluminum honeycomb core) to support the optical elements with required stiffness and thermal stability while achieving a low mass. As shown in Figure 2, the three channels and their sub-systems are nested in the very compact volume of the OBS unit $(860 \mathrm{~mm}$ x $445 \mathrm{~mm}$ x $360 \mathrm{~mm})$. The OBS unit is supported by three Titanium A-shape mounts providing thermal decoupling and isostatic mechanical interface with the spacecraft mounting panel.

The main bench is a $30 \mathrm{~mm}$ thick panel with reinforced honeycomb at the interface with the three mounts. The main bench supports most of the OBS sub-systems (summarised in Table 2). The back panel is $10 \mathrm{~mm}$ thick and holds the two primary mirrors of the HRI channels. The other OBS panels are also $10 \mathrm{~mm}$ thick but only contribute to the structural stiffness.

Under the OBS unit, the harness from the electrical sub-systems is routed toward a connector panel at the rear side. The OBS is then electrically connected to the CEB unit by an inter-connecting harness from this connector panel.
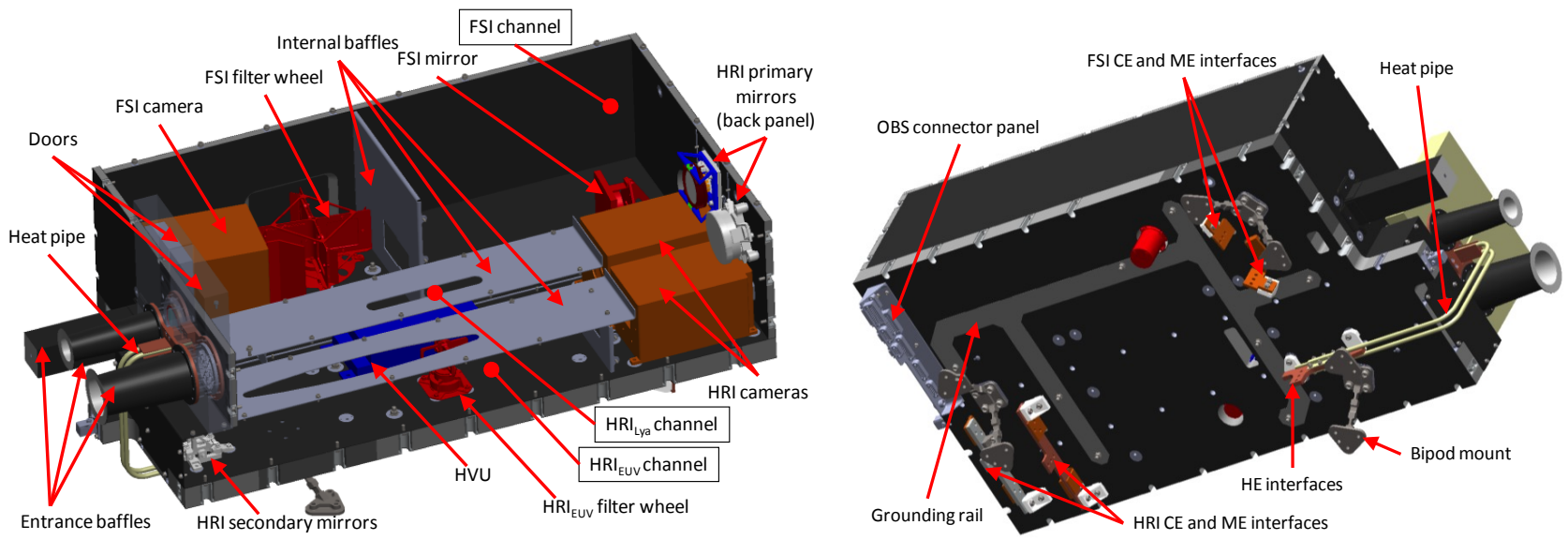

Figure 2 - EUI OBS unit overview (internal wall are here hidden)

Table 2 - EUI OBS sub-systems overview

\begin{tabular}{|c|c|c|}
\hline Sub-system & Function & Comment \\
\hline Entrance baffles & Rejection of Solar infrared (IR) and visible (VIS) & \\
\hline Doors & $\begin{array}{l}\text { Protect from contamination, acoustic and pressure } \\
\text { variation }\end{array}$ & Re-closable mechanism \\
\hline Entrance filters & $\begin{array}{l}\text { Rejection of Solar IR and VIS } \\
\text { Select bandpass }\end{array}$ & $\begin{array}{l}\text { Located in the door assemblies } \\
\quad-{\text { Aluminium foil for FSI and } \mathrm{HRI}_{\mathrm{EUV}}}-\mathrm{MgF}_{2} \text { with Aluminium coating for } \mathrm{HRI}_{\mathrm{Lya}}\end{array}$ \\
\hline Mirror(s) & $\begin{array}{l}\text { High reflective efficiency and bandpass selection } \\
\text { (mirror coating) }\end{array}$ & Two mirrors for $\mathrm{HRI}_{\mathrm{EUV}}$ and $\mathrm{HRI}_{\mathrm{Lya}}$, one mirror for FSI \\
\hline Filter wheel & Bandpass selection and redundancy & Not in $\mathrm{HRI}_{\mathrm{Lya}}$ \\
\hline Detectors & Convert photons in electrical signal & $\begin{aligned} \text { 3k } \times 3 \mathrm{k}(10 \mu \mathrm{m} \text { pitch }) \text { CMOS-APS devices: } \\
\text { - windowed to } 2 \mathrm{k} \times 2 \mathrm{k} \text { for HRI } \mathrm{HEV}_{\mathrm{EUV}} \text { and } \mathrm{HRI}_{\mathrm{Lya}} \\
\text { - back-side thinned for FSI and } \mathrm{HRI}_{\mathrm{EUV}}\end{aligned}$ \\
\hline FPA (Focal Plane Assembly) & Transfer detector signal to the CEB & Camera includes a Front-End Electronic (FEE) \\
\hline VUV Intensifier & Convert UV photons to VIS photons & In HRI $_{\text {Lya }}$ \\
\hline High Voltage Unit & Provide required voltage to intensifier & In $\mathrm{HRI}_{\text {Lya }}$ \\
\hline
\end{tabular}




\section{Thermal design}

The EUI instrument is an internally mounted unit. The CEB is radiatively and conductively coupled with the spacecraft structure. The OBS is however a thermally insulated unit that remains in an acceptable temperature range in hot and cold flight environment, with low conductive link to the platform (low conductance mounts) and radiative insulation (MLI).

The thermal design of the EUI OBS unit also takes into account the specific thermal environment of the Solar Orbiter mission and, in particular, of the 13 solar constants solar heat flux $\left(17.5 \mathrm{~kW} / \mathrm{m}^{2}\right)$ at perihelion. The front of the OBS unit (doors and entrance baffles) is consequently thermally decoupled from the rest of the OBS unit to limit thermo-elastic deformation and ensure the optical performance over the operational temperature range. It is however thermally coupled with the spacecraft by two redundant heat pipes to evacuate the solar and infrared heat absorbed by the entrance baffles and filters.

The EUI detectors must be cooled at a temperature lower than $-40{ }^{\circ} \mathrm{C}$ (target $-60{ }^{\circ} \mathrm{C}$ ) with a stability of $\pm 5^{\circ} \mathrm{C}$. The OBS unit is also, therefore, thermally coupled to some spacecraft radiators through dedicated thermal straps, allowing the transfer of dissipated heat by the detectors (through a Cold Element interface - CE) and by the camera electronics boards (Medium Element interface - ME), as shown on Figure 3. Because of spacecraft constraints, the two HRI share a common $\mathrm{CE}$ and common $\mathrm{ME}$ interface with the spacecraft, while the FSI has its own CE and ME interfaces.

\section{Detectors}

The EUI cameras are based on $3 \mathrm{k} \times 3 \mathrm{k}$ $10 \mu \mathrm{m}$ pitch CMOS-APS detectors (windowed to $2 \mathrm{k} \times 2 \mathrm{k}$ in the HRI cameras).

The EUI detectors operate in a shutterless and a non destructive readout mode. They have a high radiation tolerance $(>100 \mathrm{krad}$ TID), with low power consumption $(<1 \mathrm{~W})$, and relatively high operational temperature $\left(-40{ }^{\circ} \mathrm{C}\right)$. They also allow a high readout speed ( $>1$ full frame per second) with a low readout noise and a high dynamic range (5 to 80000 electrons).

The $3 \mathrm{k} \times 3 \mathrm{k}$ detectors are stitched devices, based on the architecture shown in Figure 4. Two output gains are implemented per pixel to achieve a low readout noise and a high full well capacity. The outputs are multiplexed and externally converted to digital signal.

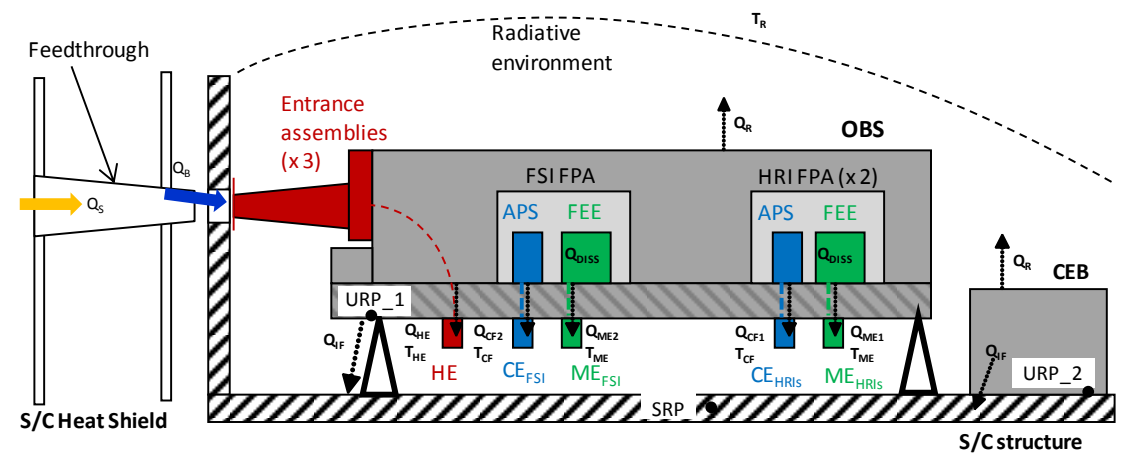

Figure 3 - EUI OBS thermal interfaces

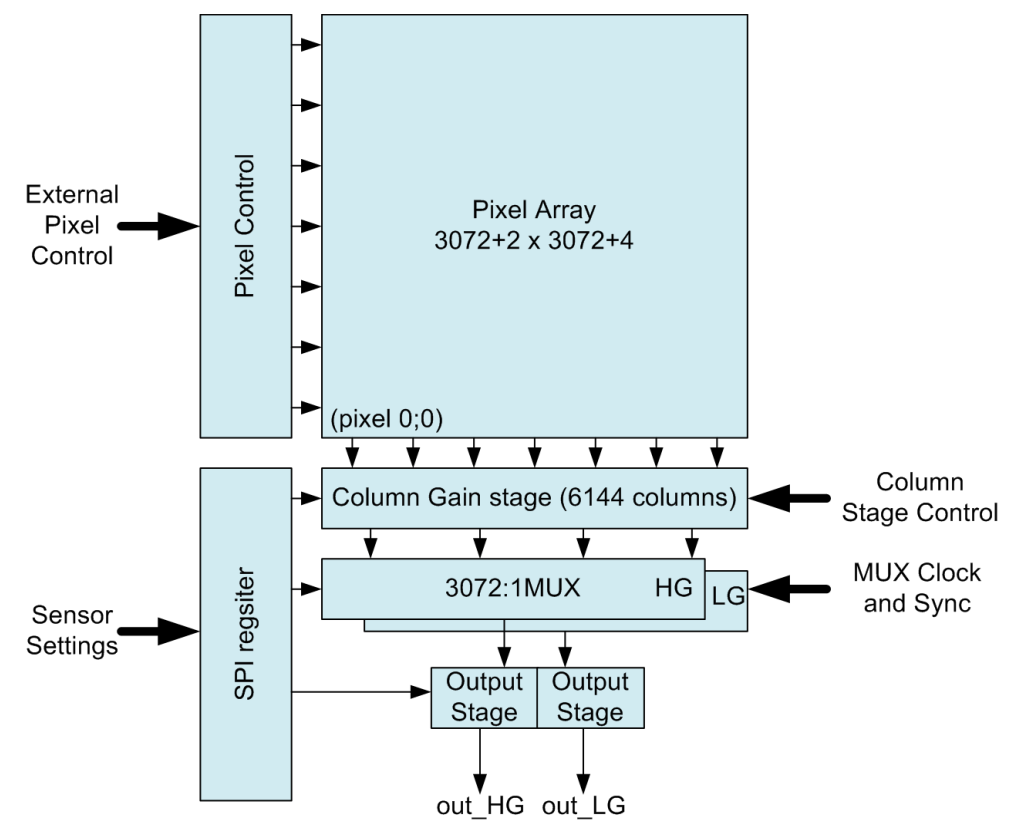

Figure 4 - EUI detector architecture block diagram. 
The FM detector package is made of aluminum nitride (AIN) ceramic to match the thermo-elastic coefficient (CTE) of the silicon die and to provide high thermal conductivity $(150 \mathrm{~W} / \mathrm{mK})$ for a limited mass.

The package of the FSI and $\mathrm{HRI}_{\mathrm{EUV}}$ detectors are isostatically mounted in the camera by titanium blades, and thermally connected to cooling straps (Figure 5). For the $\mathrm{HRI}_{\text {Lya }}$, the package is fixed to the camera via the intensifier mechanical interface.

It is electrically connected to the camera front-end electronic by a dedicated harness via a miniaturized connector (for integration and dismounting facility).

\section{Cameras}

The three EUI cameras share a common mechanical and thermal design concept, based on a common detector (CMOS APS) thermally decoupled from the camera housing and boards, each camera being adapted to the constraints of its position within the OBS unit (focal plane position, allocated volume, position w.r.t. thermal interface with spacecraft, etc). Figure 6 shows the FSI camera.

The electronic concept of the EUI cameras shares a quasi-identical design. The main components of each camera Front-End Electronic (FEE) are:
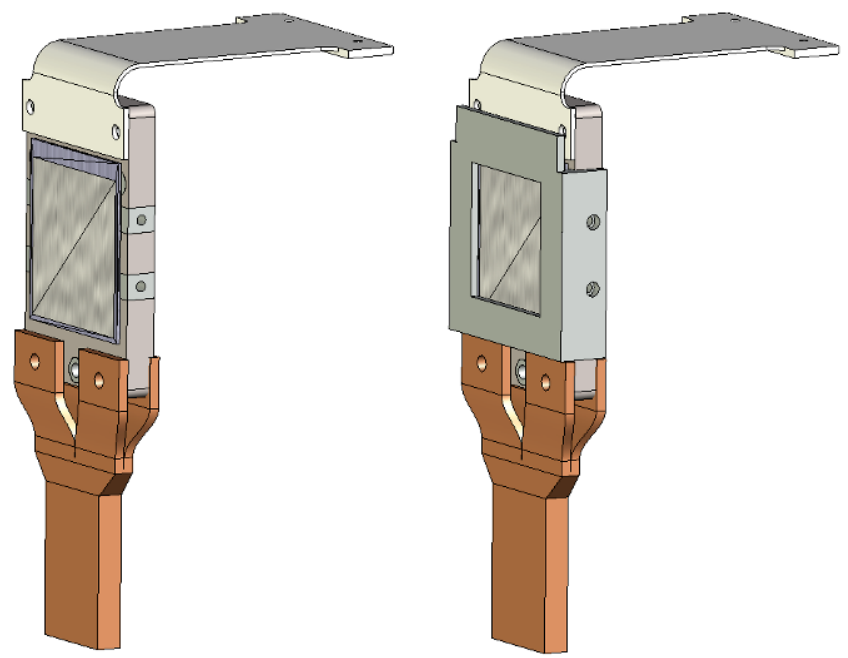

Figure 5 - EUI FM detector package (left: FSI and HRI $\mathrm{EUV}_{\mathrm{V}}$ channels, right: with support for intensifier gluing in $\mathrm{HRI}_{\text {Lya }}$ )

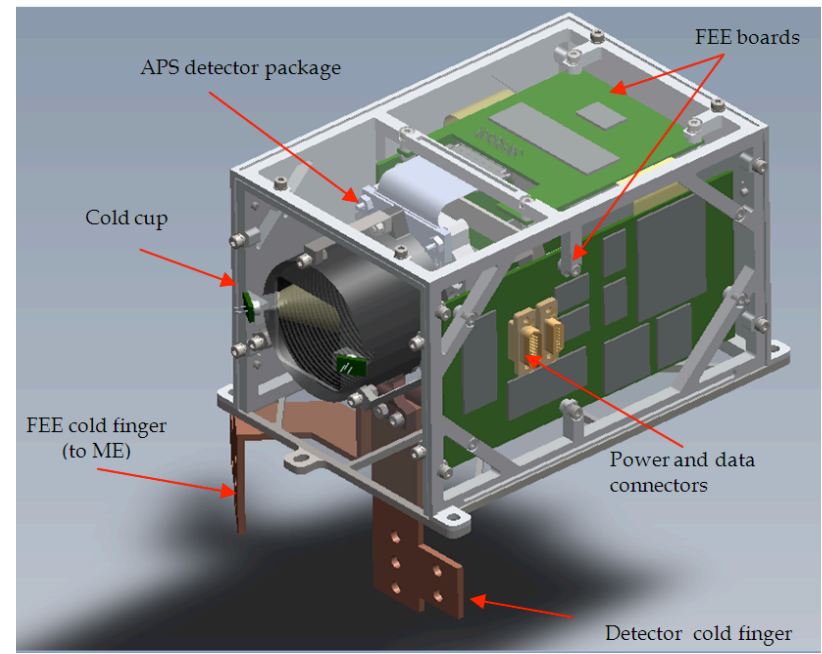

Figure 6 - EUI camera (FSI channel)

- $\quad$ A $3 \mathrm{k}$ x $3 \mathrm{k}$ CMOS-APS sensor (windowed to $2 \mathrm{k}$ x $2 \mathrm{k}$ for the HRI channels)

- An FPGA (control sensor, ADC, SDRAM and housekeeping (HK), manage data interface with CEB, drive calibration LED, provide all clocks derived from the main clock)

- $\quad$ A clock (provided by an external oscillator) running at $80 \mathrm{MHz}$

- An LVDS Driver/Receiver (electrical level for data interfaces between the FEE and the CEB)

- $\quad$ Two 14 bits Analog to Digital Converters (12 ENOB) working in parallel outputs at $30 \mathrm{Msps}$

- An SDRAM memory to buffer image before transfer to the CEB

- An analog conditioning (sensor biasing, LED control, HK) and power conditioning (secondary voltages)

- $\quad$ A latchup protection (for ADC, APS, and SDRAM)

- A multiplexer of the HK data

The $\mathrm{HRI}_{\text {Lya }}$ camera comprises a micro-channel plate intensifier which is a closed unit held under vacuum by a $\mathrm{MgF}_{2}$ entrance window and a fiber optic output window (Figure 7). It comes with an external High Voltage supply Unit (HVU) (Figure 8). The micro-channel plate front side represents the focal plane position. It has a potassium bromide (KBr) photocathode to maximize the quantum efficiency at the Lyman- $\alpha$ wavelength $(121.6 \mathrm{~nm})$ and, at the same time, reduce 
the sensitivity at longer wavelengths. The anode of the intensifier is a phosphor screen on the fibre optic output window. An additional fiber optic taper is glued to the output window, to reduce by a factor of 1.41 the size of the image from 40 $\mathrm{mm}$ diameter at the intensifier to the diagonal of the image sensor. The fiber optic taper is coupled with the image sensor by direct contact with the active area of the sensor and mechanically stabilized by epoxy gluing with the sensor package.

The Lyman- $\alpha$ intensifier tube requires regulated high voltages of $1 \mathrm{kV}$ and $6 \mathrm{kV}$ for the MCP and the phosphor SCREEN. A HVU power supply switches an isolated secondary power to obtain these voltages up to a maximum of 7 $\mathrm{kV}$. Differential analogue lines from the CEB control the two high voltage outputs. Differential analogue outputs are fed back to the CEB to monitor the HVU outputs. The HVU provides high voltage panel connectors on the backside of the housing. Pigtail cables for SCREEN and MCP are soldered on the intensifier side and plugged to the panel connectors on the HVU. The HVU is mounted within a dedicated housing located on the optical bench inside the EUI instrument. It is hermetically sealed w.r.t. the optical housing. The HVU can be configured to operate at reduced voltage, to avoid HV hazards under atmospheric pressure conditions.

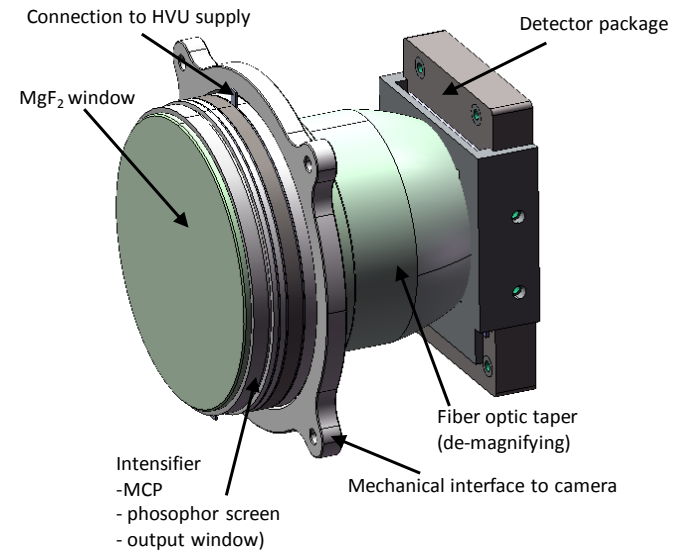

Figure $7-\mathrm{HRI}_{\text {Lya }}$ intensifier overview

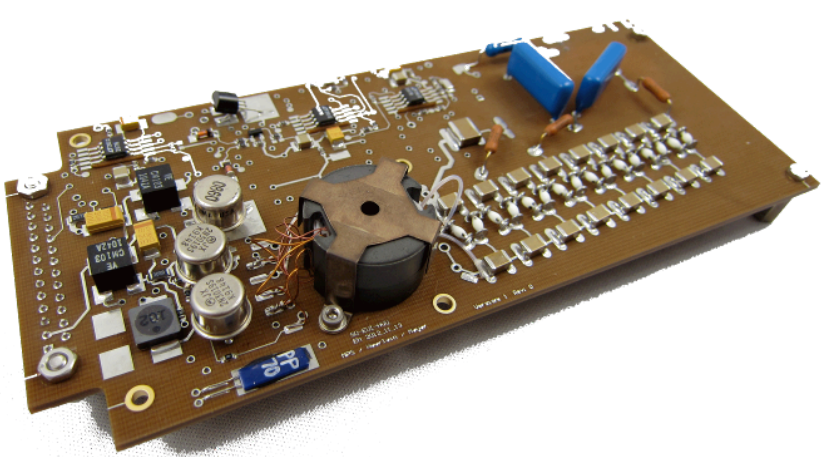

Figure 8 - HVU electronic board

\section{Optical design}

The two HRI units share a quasi-identical optical design. It is based on an off-axis Gregory telescope for the HRI $\mathrm{Lya}_{\text {a }}$ channel and an off-axis Cassegrain telescope for the $\mathrm{HRI}_{\mathrm{EUV}}$ channel, both optimized in length and width, with a $30 \mathrm{~mm}$ and a $47.4 \mathrm{~mm}$ diameter entrance pupil, respectively, located at the front section of their entrance baffles (Figure 9). The optical design parameters are detailed in Table 3. The Gregory design allows using a field stop in the light path combined with internal baffles walls to strongly limit the straylight from outside of these channel's field of view. The Gregory is however very sensitive to alignment tolerances and a Cassegrain layout has therefore been considered for the $\mathrm{HRI}_{\mathrm{EUV}}$ channel to reduce sensitivity to the alignment, with the drawback of less efficient baffling (no intermediate focus and field stop).

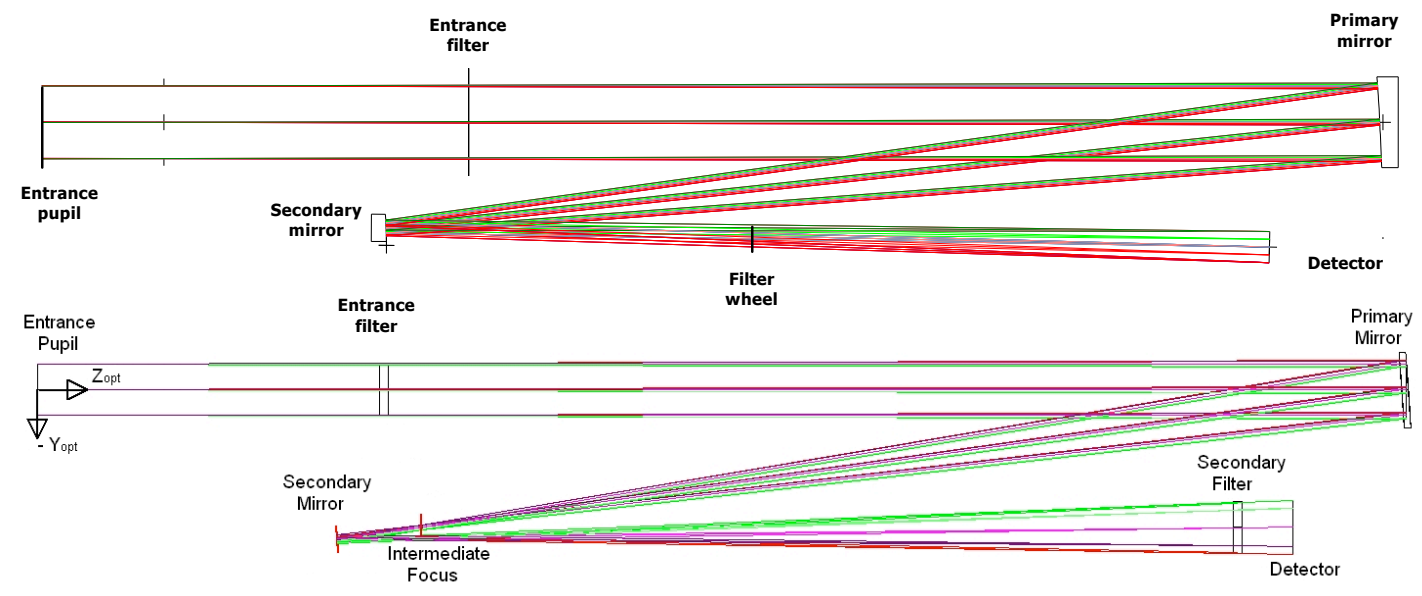

Figure 9 - EUI HRI optical layouts (top: HRI EUV channel, bottom: HRI Lya channel) 
Tolerance analyses have been performed to evaluate the capability of the concept to maintain good image quality with an opto-mechanical structure submitted to the varying thermal conditions associated with the Science Operation Windows throughout the orbit. The resulting requirements for the thermo-mechanical environment dictate that a CFRP composite structure combined with fused silica mirrors (Figure 10) and Invar mirror mounts is required for the $\mathrm{HRI}_{\mathrm{EUV}}$ channel and Zerodur mirrors with Titanium mounts for the $\mathrm{HRI}_{\text {Lya }}$ channel to maintain the required performances considering the expected thermal excursions.
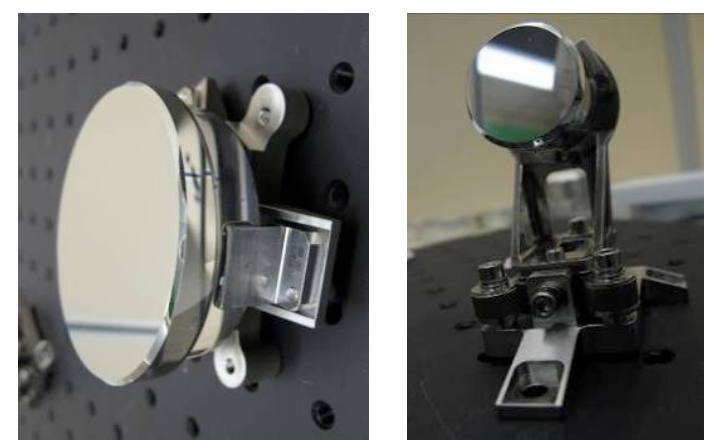

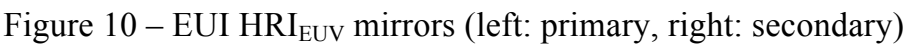

For the HRI $\mathrm{EUV}_{\mathrm{V}}$ channel, one aluminium foil filter is inserted between the entrance aperture (entrance pupil) and the primary mirror to provide protection against excessive heat input on the mirror and efficient rejection of the visible light. A filter wheel, comprising two redundant EUV filters, one open and one occulting position, is located at the output pupil. The front and rear EUV filter are of primary importance for the instrument to suppress the visible light that can be $10^{8}$ times more intense than the EUV flux. The EUV reflective coatings of the mirrors are specific multilayers optimized to provide the desired scientific spectral passbands. Their design takes into account the angle of incidence on the mirrors, the variations of which are small enough so that no compensation is needed.

The Lyman- $\alpha$ channel mirrors use $\mathrm{MgF}_{2} / \mathrm{Al}$ (magnesium fluoride/ aluminium) coating providing a reflectivity at 121.6 nm over $75 \%$. A broad-band $\mathrm{MgF}_{2}$ interference filter is used at the entrance of the telescope to isolate the spectral line at $121.6 \mathrm{~nm}$ and reject visible and infrared light as well as EUV and X-rays, protecting the mirror coatings. A narrow-band filter is placed in front of the detector to further isolate the Lyman- $\alpha$ line and achieve the spectral purity. The combination with a solar-blind detector yields a spectral purity larger than $90 \%$ for Lyman- $\alpha$ in the quiet Sun and higher purity in the active regions, and is tolerant to potential spectral shifts due to thermal effects. The magnesium fluoride substrate material of the filters is sufficiently radiation hard so as to provide the thermal heat load protection with minimal degradation during the mission. The detector of the Lyman- $\alpha$ channel will be a solar-blind, intensified $2 \mathrm{k} x 2 \mathrm{k}$ CMOS active pixel sensor (I-APS) with a sensitive aperture of $32 \times 32 \mathrm{~mm}$. The image of the intensifier is transferred by a fibre optic taper to the actual size of the CMOS/APS sensor providing an image scale of 1 arcsec on two pixels.

Table 3 - Design parameters of the HRIEUv and HRI Ly- channels

\begin{tabular}{|c|c|c|}
\hline & HRI $_{\text {EUV }}$ & HRI $_{\text {Ly- } a}$ \\
\hline Focal length & $4187 \mathrm{~mm}$ & $5804 \mathrm{~mm}$ \\
\hline Entrance pupil & $\phi 47.4 \mathrm{~mm}$ & $\phi 30 \mathrm{~mm}$ \\
\hline Field of view & 1000 arcsec square & 1000 arcsec square \\
\hline Plate scale & 50 arcsec $/ \mathrm{mm}$ & 31.5 arcsec $/ \mathrm{mm}$ (w/o intensifier taper) \\
\hline & $66 \mathrm{~mm}$ diameter $(54 \mathrm{~mm}$ useful) & $42 \mathrm{~mm}$ diameter (36 mm useful) \\
Primary mirror (M1) & $80 \mathrm{~mm}$ off-axis & $80 \mathrm{~mm}$ off-axis \\
& $\mathrm{R}=1518.067 \mathrm{~mm} \mathrm{CC}, \mathrm{K}=-1$ & $\mathrm{R}=1143 \mathrm{~mm}$ CC, $\mathrm{K}=-1$ \\
\hline & $25 \mathrm{~mm}$ diameter $(12 \mathrm{~mm}$ useful) & $20 \mathrm{~mm}$ diameter (18 mm useful) \\
Secondary mirror (M2) & $11.44 \mathrm{~mm}$ off-axis & $7 \mathrm{~mm}$ off-axis \\
& $\mathrm{R}=256.774 \mathrm{~mm} \mathrm{CX}$ & $\mathrm{R}=91 \mathrm{~mm}$ CC \\
& $\mathrm{K}=-2.04$ & $\mathrm{~K}=-0.65$ \\
\hline
\end{tabular}

The FSI optical design is based upon a single off-axis mirror (Herschelian telescope) making an image of a 3.8 deg x 3.8 deg FOV through a 5-mm entrance pupil located at $740 \mathrm{~mm}$ from the mirror (equivalent focal length is $462.03 \mathrm{~mm}$ ) as shown on Figure 11, with parameters listed in Table 4. A thin film aluminium filter is positioned $240 \mathrm{~mm}$ behind the entrance pupil. This filter rejects the visible light and the IR, letting only the EUV through. The $174 \AA$ and $304 \AA$ FSI wavebands are selected using thin (zirconium) and $\mathrm{Al} / \mathrm{Mg} / \mathrm{Al}$ (aluminium / magnesium / aluminium) filters mounted on a filter wheel. The special multilayer coating of the mirror is optimized for high reflectance at both wavelengths. 


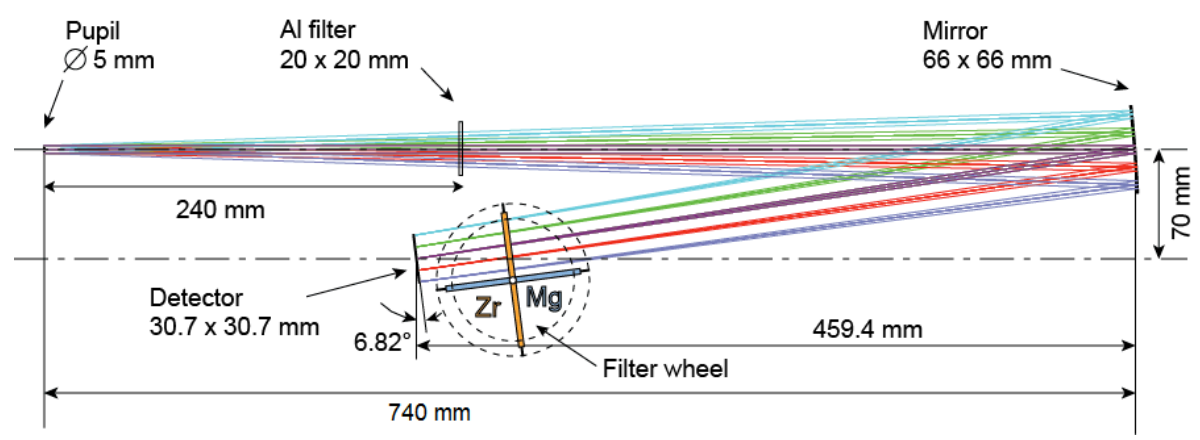

Figure 11 - EUI FSI optical layout

Table 4 - Design parameters of the FSI channel

\begin{tabular}{|l|l|}
\hline Optical element & Parameters \\
\hline Entrance pupil & Shape: hexagonal, 5 mm edge \\
\hline Distance Pupil - M1 & $740 \mathrm{~mm}$ \\
\hline Mirror M1 & $\begin{array}{l}\text { Figure: off-axis ellipsoid, conic }=-0.732 \\
\text { Shape: square } 66 \mathrm{~mm} \times 66 \mathrm{~mm} \\
\text { Off-axis: } 70 \mathrm{~mm} \text { - Focal length: } 462.5 \mathrm{~mm}\end{array}$ \\
\hline Distance M1 - Focal plane & $462.03 \mathrm{~mm}$ (along optical axis) \\
\hline Detector & $\begin{array}{l}\text { Figure: flat square } 30.72 \mathrm{~mm} \times 30.72 \mathrm{~mm} \\
\text { Pixels: } 3072 \times 3072 \\
\end{array}$ \\
& Tilt to optical axis : $6.82^{\circ}$ \\
\hline
\end{tabular}

\section{Mechanisms}

As part of the OBS unit, there are five mechanisms: three doors and two filter wheels.

\section{- $\quad$ Filter wheels}

For spectral purity and redundancy, a second filter is located in the optical path of each channel, as close as possible to the focal plane (so-called 'focal filter'). In the HRI $\mathrm{EUV}_{\mathrm{V}}$ and FSI channels these focal filters are mounted on a paddle type filter wheel mechanism (Figure 12).
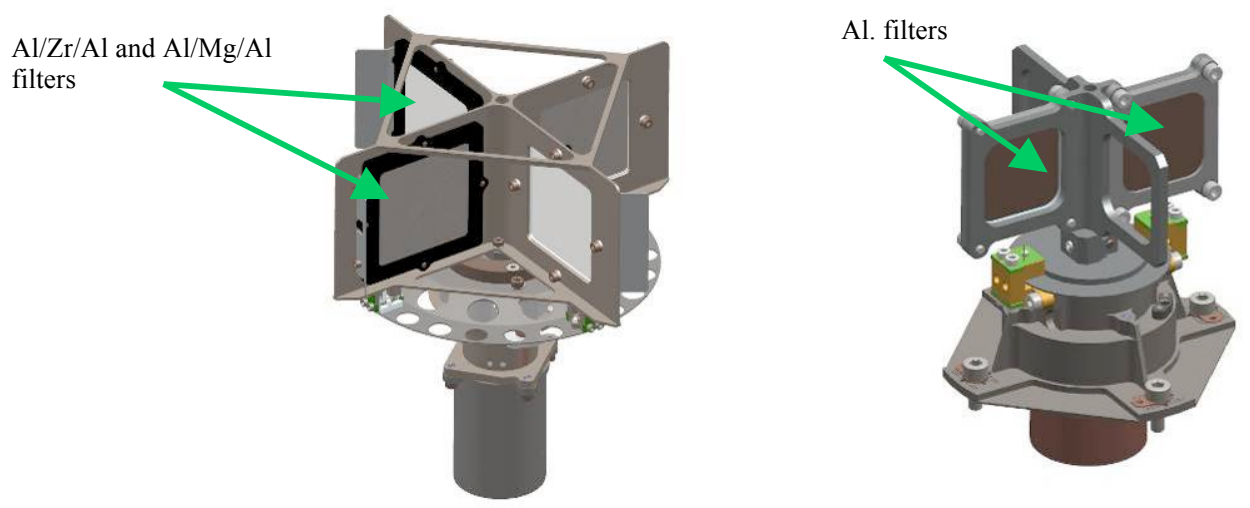

Figure 12 - EUI filter wheels (left: FSI, right: $\mathrm{HRI}_{\mathrm{EUV}}$ )

For the FSI channel, the focal filter is also used to select one or the other of the two passbands reflected by the multilayers mirrors. The baseline is $\mathrm{Al} / \mathrm{Zr} / \mathrm{Al}$ and $\mathrm{Al} / \mathrm{Mg} / \mathrm{Al}$ sandwich filters. The FSI filter wheel is a rotational mechanism equipped with two pairs of such filters, positioned at 90 degrees w.r.t. each other. The FSI filter wheel allows choosing between two wavelengths, one at $17.1 \mathrm{~nm}$ the other at $30.4 \mathrm{~nm}$. The second use of this filter wheel is to protect the detector from EUV radiation damage; it is the occulting position. This position is obtained geometrically by positioning the wheel close to $45^{\circ}$, as shown in Figure 13. 

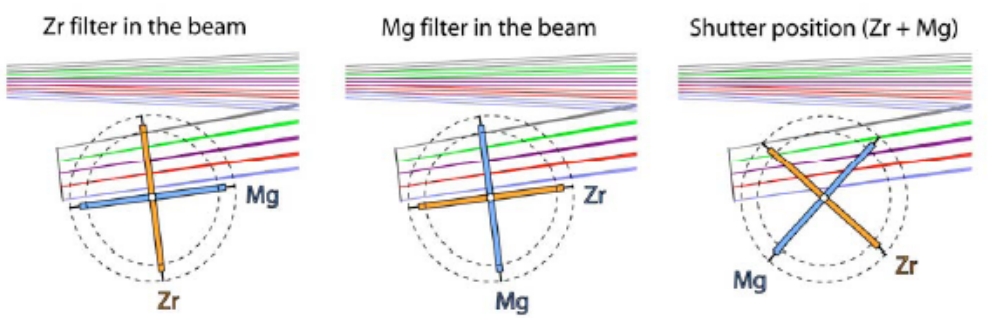

Figure 13 - FSI filter wheel operating modes

The filters are fixed on a structure linked to the motor by the means of a casing frame. The structure is mounted on the motor by the intermediate of an elastic coupling and a pair of bearings. This inhibits transferring any mechanical loads on the motor. The whole assembly is also mechanically equilibrated to minimize stress on the fragile filters. The drive train is a stepper motor (Phytron type with 200 steps) that is driven by the CEB. To avoid any shock on the filters, the motor is commanded is in $1 / 16^{\text {th }}$ of a step corresponding to $1.8^{\circ}$. Figure 14 shows an exploded view of the FSI filter wheel mechanism.

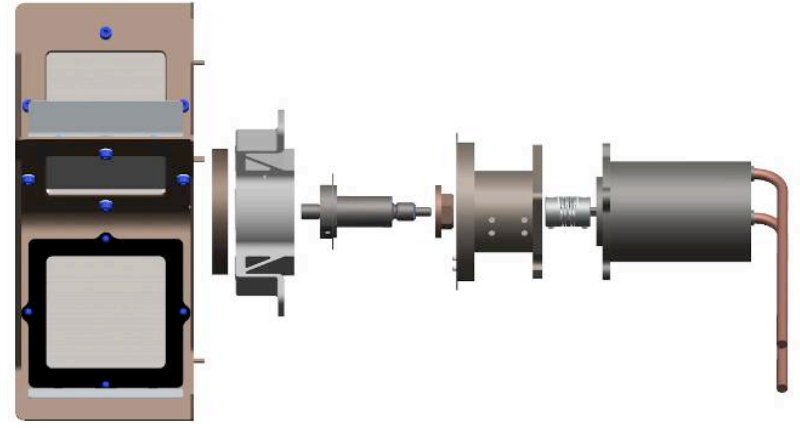

Figure 14 - FSI filter wheel exploded view

For scientific reasons, the knowledge of the filter angular position must be more precise than one motor step size. This mechanism is equipped with sensors to discriminate between the kind of filters and for checking their position with a precision inferior to $0.8^{\circ}$. As shown in Figure 15, the beam of a diode is hidden by a small mask of the filter wheel when a filter is at the desired position. The mask width is designed to correspond to one step of the motor. In a first time, the filter wheel is positioned on the bench such as a filter is perpendicular to the beam at $+/-1^{\circ}$. In a second time, the sensors are positioned on the middle of the mask which ensures precise positioning information of the filter when the motor power is off. There are three masks and four pairs of LED/photo-transistors. This combination allows us to discriminate the filter positioning.

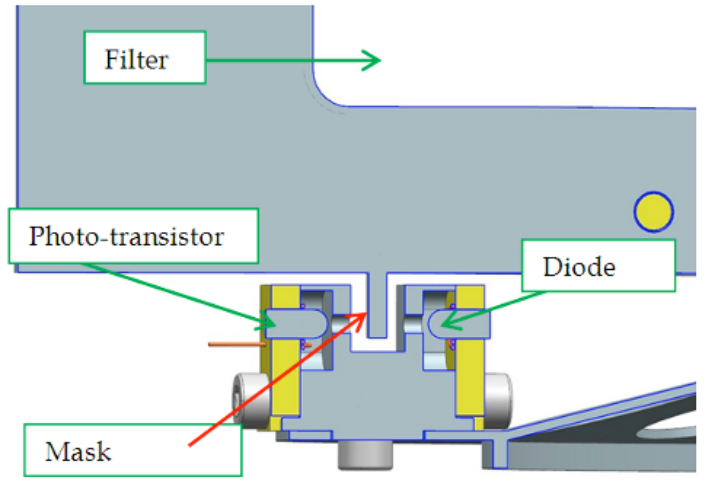

Figure 15 - FSI filter wheel sensor scheme

For the HRI $\mathrm{EUV}_{\mathrm{E}}$ channel, the focal filter is an aluminum foil similar to the EUV entrance filters. The HRI filter wheel allows choosing between three operating modes: a filter position (nominal and redundant filters), an occulting position, and an opened position. The wheel is directly fixed on the stepper motor shaft and is made of Aluminum 6061 with an interface structure in TiA6V. The assembly is fixed on the optical bench by four screws; the thermal expansion of the interface structure is enabled by a special cutting. On $\mathrm{HRI}_{\mathrm{EUV}}$, the motor current of the filter wheel is monitored by the CEB. A zero position is necessary to re-initiate the mechanism. The zero position is obtained by the same sensor than the FSI filter wheel mechanism with the mask replaced by a hole to achieve a resolution of 1.8 degrees.

\section{- Doors}

The EUV front filter needs a protection against air pressure, and the three channels need a contamination barrier. A door mechanism combining these two functions is located at the end of the entrance baffles. This door mechanism will also provide a protection from launch acoustic loads for the entrance filter nested in the door assembly.

The FSI door will also provide an occulter position to hide the Sun (1.2 solar radius when at $0.45 \mathrm{AU})$ and perform some coronographic measurement in the EUV (Figure 16). 

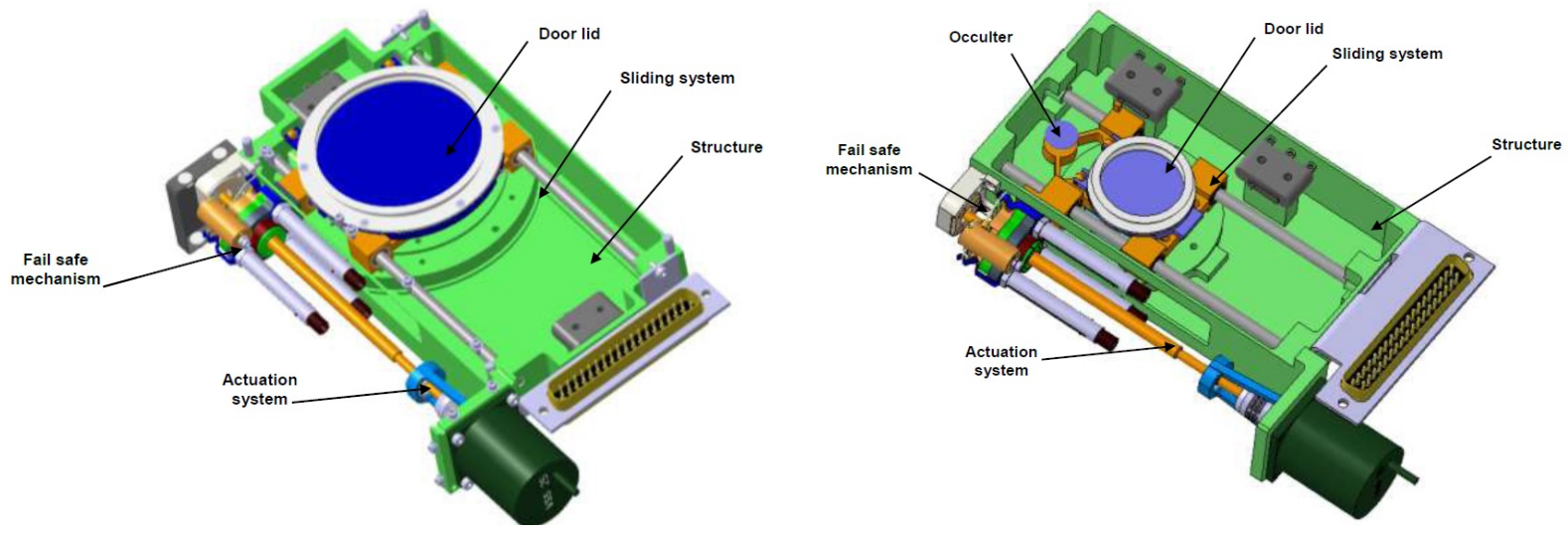

Figure 16 - HRI (left) and FSI (right) door mechanisms

The EUI internal door mechanisms are mounted to the front panel of the OBS, located at the end of the entrance baffles (HRI channels) and inside the cavity (FSI channel). The design is based on a sliding door, similar to a vacuum gate valve that closes laterally on two sides against a seal. The drive train provides the linear sliding motion and the lateral expansion of the door lid. It is based on a stepper motor drive with a lead screw that moves two lids along two parallel guiding rails (Figure 16). In case of failure of the driving mechanism, a fail-safe mechanism can be engaged that operates a spring-loaded device to move the door lids to the open position.

\subsection{CEB unit}

The CEB is an aluminum box (Figure 17) that contains four main PCBs (compression board, processor board, power supply board and auxiliary board) which are mechanically and thermally coupled with the CEB housing.

The function of the CEB four main boards are summarized in Table 5. There is a fifth board in the CEB, the Mother Board, which provides the interconnect function between the four main boards.

The CEB has nine connectors for the EUI internal harness (data, control and power transfer from CEB to OBS), four connectors for the $\mathrm{S} / \mathrm{C}$ harness (nominal and redundant power and data interfaces), and one test connector.

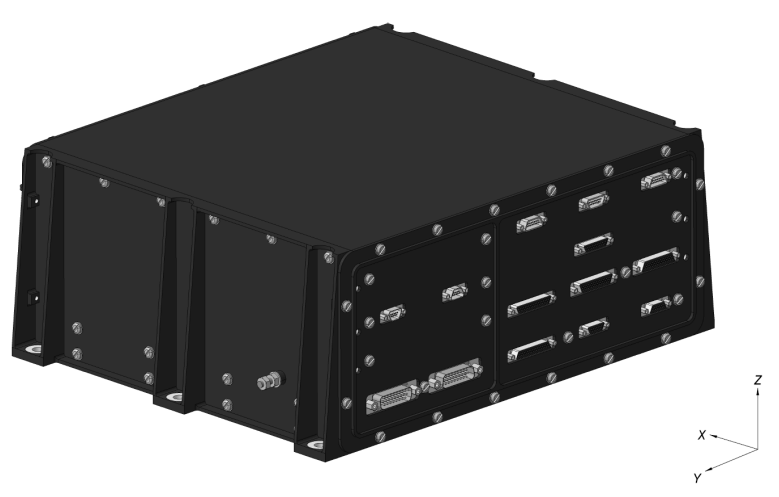

Figure 17 - EUI CEB unit overview

Table 5 - EUI OBS CEB unit boards

\begin{tabular}{|c|c|}
\hline PCBs & Function \\
\hline Compression Board & Connects to the three FEE digital interfaces \\
\hline Processor Board & Connects to the spacecraft digital interfaces \\
\hline Auxiliary Board & $\begin{array}{cl}\text { Connects to the OBS auxiliary functions: } \\
- & \text { Temperature sensors } \\
- & \text { Motor drive and position sensing } \\
- & \text { Heaters } \\
- & \text { Control and monitoring of HV PSU }\end{array}$ \\
\hline Power Supply Board & $\begin{array}{l}\text { Houses four PSUs, one for the CEB and one for each of } \\
\text { the three cameras }\end{array}$ \\
\hline
\end{tabular}

The power and data interfaces with the spacecraft are handled by the CEB, which contains DC/DC converters that provides all the isolated secondary supplies needed by the instrument (apart from the high voltage needed by the Lyman$\alpha$ intensifier).The power interface will support the main and redundant power systems to be provided by the spacecraft. 
Sensitive secondary rails will be distributed without a ground reference to allow a ground reference to be locally defined at or near the FEE. The power rails used by the CEB are regulated and those for the telescopes are unregulated. The CEB also contains power monitoring, current limiting, and secondary power switching functions and circuitry to control the five mechanisms.

The CEB also contains the instrument's data processing unit and logic interfaces to the spacecraft and telescopes. The data processing unit, spread across two boards, includes memory for the onboard code, mass memory for 'pre-trigger' data and data selection, FPGAs to implement the logic interfaces to the telescopes, APS pixel pre-processing and a compression system. The logic interface to the spacecraft is a dual cold redundant SpaceWire interface supported by the UT699 processor of Gaisler/Aeroflex. The logic interfaces to each of the telescopes are implemented using bespoke data and strobe encoded serial interface over a LVDS physical layer. These interfaces are used for Command, Command Acknowledgement, Housekeeping and Science data.

The CEB will provide all the functionality required to operate the instrument. The functions include:

- $\quad$ SpaceWire interface to the spacecraft DMS,

- Autonomy, data compression, selection, packetisation and storage, and event triggering,

- Command reception and decoding, mechanism control and monitoring,

- Thermal control and instrument status/health monitoring, HK monitoring and transmission,

- Watchdog to monitor program flow, standardized command and data interface from the telescopes.

These functions are under the control of the processor system resident in the CEB unit. The command and $\mathrm{HK}$ interface is part of the HSL interface.

The on-board software uses the RTEMS real-time operating system to allow tasks of higher priorities take precedence over tasks of lower priorities and other tasks to run when the current task has to wait. Communication between interrupt handlers and tasks will be using RTEMS events and messages. The software is split into two separate pieces of code and several instrument modes and sub-modes related to different power, data and operational requirements, as summarised in Figure 18.

A typical power dissipation profile is given in Figure 19 showing the average and peak power variations for a typical 10 days nominal observation period (3 channels, including filter wheel operations). The filter wheel operation corresponds to a recurrent peak power. Internal door opening, calibration sequences, and detector annealing should be ideally performed before each nominal operations sequence (i.e. before each 10 days observation periods). The filter wheel moves during 10 seconds with an additional 2 seconds to stabilise (upper duration limit). Typically such operation is repeated every 10 minutes during nominal mode and every few hours during synoptic mode. The internal door operations are only performed before and after each nominal observation sequence (science mode), and last a few seconds.

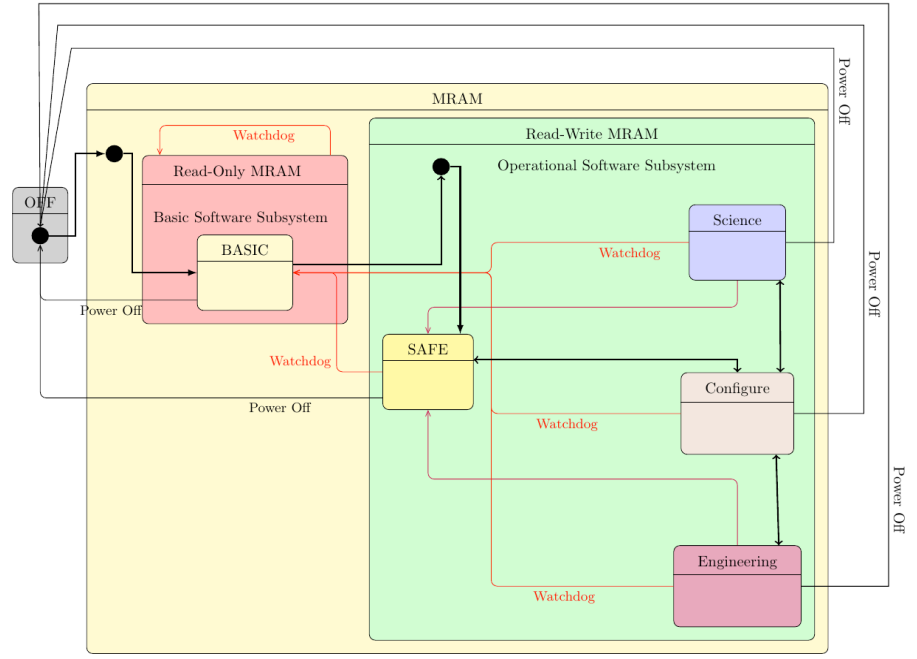

Figure 18 - EUI operational mode block diagram

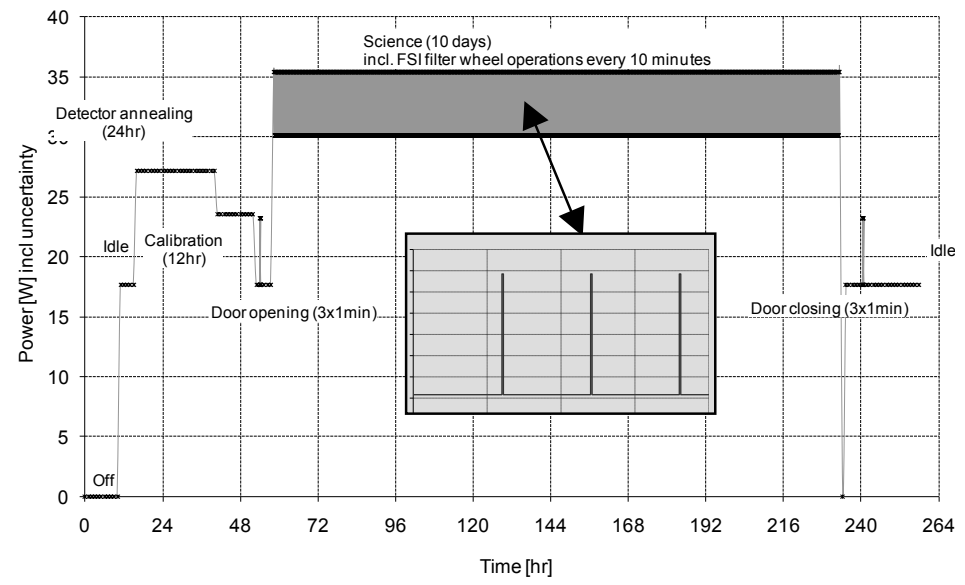

Figure 19 - EUI power consumption profile over the science nominal mode 


\subsection{Instrument datasheet}

The EUI instrument can be summarised with the numbers listed in the instrument datasheet (Table 6).

Table 6 - EUI instrument datasheet

\begin{tabular}{|c|c|c|}
\hline Name / acronym & \multicolumn{2}{|l|}{ Extreme-Ultraviolet Imager / EUI } \\
\hline Objectives & \multicolumn{2}{|c|}{ EUI provides image sequences of all solar atmospheric layers above the photosphere. } \\
\hline General description & \multicolumn{2}{|c|}{ EUI consists of two high resolution imagers (HRI) and one dual-band full Sun imager (FSI). } \\
\hline Heritage & \multicolumn{2}{|l|}{ SOHO-EIT, STEREO-SECCHI-EUVI, PROBA2-SWAP } \\
\hline Parameter & Value / Description & Remarks \\
\hline \multicolumn{3}{|l|}{ Sensor / detector } \\
\hline Type & back-thinned APS CMOS & $3 \mathrm{k} \times 3 \mathrm{k}$ stitched $10 \mu \mathrm{m}$ pixels \\
\hline Operating T & $-40^{\circ} \mathrm{C}$ & Target $-60^{\circ} \mathrm{C}$ \\
\hline \multicolumn{3}{|l|}{ Optics } \\
\hline Type & Reflective & One and two mirrors schemes \\
\hline FOV & 3.8 arcdeg and 0.283 arcdeg & FSI channel and HRI channels \\
\hline Energy passband & Coronal lines & $174 \mathrm{~nm}, 304 \mathrm{~nm}, 1216 \mathrm{~nm}$ \\
\hline Pointing & Sun centre & \\
\hline \multicolumn{3}{|l|}{ Configuration } \\
\hline Physical Units & Two units: OBS and CEB & \\
\hline Location $\mathrm{S} / \mathrm{C}$ & Behind heat shield & Remote sensing instrument \\
\hline \multicolumn{3}{|l|}{ Physical } \\
\hline Total Mass & $24.93 \mathrm{~kg}$ & Allocated $23.5 \mathrm{~kg}$ \\
\hline Optical unit & $860 \times 445 \times 360 \mathrm{~mm}$ & OBS unit \\
\hline Electronic unit & $300 \times 250 \times 177 \mathrm{~mm}$ & CEB unit \\
\hline \multicolumn{3}{|l|}{ Power } \\
\hline Average & $30.1 \mathrm{~W}$ (peak $39.2 \mathrm{~W}$, standby $17.7 \mathrm{~W}$ ) & Allocated $30 \mathrm{~W}$ \\
\hline \multicolumn{3}{|l|}{ Data rate / volume } \\
\hline Average data rate & Allocated 20.5 kbps over 30 days, including housekeeping. & \\
\hline Own data storage & 1.6 GByte & 3D-plus 4 Gbit modules \\
\hline \multicolumn{3}{|l|}{ Thermal } \\
\hline Heat load to radiators & $\begin{array}{l}35 \mathrm{~W} \text { from OBS } \\
23 \mathrm{~W} \text { from CEB }\end{array}$ & Including $8 \mathrm{~W}$ radiatively to $\mathrm{S} / \mathrm{C}$ \\
\hline Operating $\mathrm{T}$ range & $+50 /-20^{\circ} \mathrm{C}$ & \multirow{2}{*}{$\mathrm{S} / \mathrm{C}$ environment temperature } \\
\hline Non-operating range & $+60 /-30^{\circ} \mathrm{C}$ & \\
\hline \multicolumn{3}{|l|}{ Cleanliness } \\
\hline DC magnetic & Allocated $120 \mathrm{~mA} \cdot \mathrm{m}^{2}(250 \mathrm{nT}$ at $1 \mathrm{~m})$ & \\
\hline Particulate & $50 \mathrm{ppm}$ & \multirow{2}{*}{ Inside OBS unit } \\
\hline Molecular & $50 \mathrm{ng} / \mathrm{cm}^{2}$ & \\
\hline \multicolumn{3}{|l|}{ Miscellaneous } \\
\hline Mechanisms & 3 internal doors and 2 filter wheels & \\
\hline Alignment & Co-aligned better than 1 arcmin between EUI channels & \\
\hline
\end{tabular}

\section{STRUCTURAL AND THERMAL MODEL}

The OBS STM units (Figure 20) are mostly flight representative, with some sub-systems replaced by dummy masses (Table 7) to be sufficiently representative for the correlation of the mechanical and thermal mathematical models.

Table 7 - EUI STM representativity

\begin{tabular}{|l|c|c|c|}
\hline & Mechanical & Thermal & Flectrical \\
\hline Structure and thermal hardware & Flight like & \multicolumn{3}{|c|}{ Dummy masses } \\
\hline Doors & \multicolumn{3}{|c|}{ Test heaters and thermal sensor } \\
\hline Entrance filters and baffles & Flight like & Dummy masses & Flight like \\
\hline Cameras & Flight like & Flight like & Test heaters and thermal sensor \\
\hline HVU & Flight like & Flight like & Test heaters and thermal sensor \\
\hline Mirrors and mount & Flight like & Dummy masses \\
\hline Filter wheels & & Flight like \\
\hline Harness and connectors & Flight like & \multicolumn{3}{|c|}{ Test heaters and thermal sensor } \\
\hline CEB & &
\end{tabular}



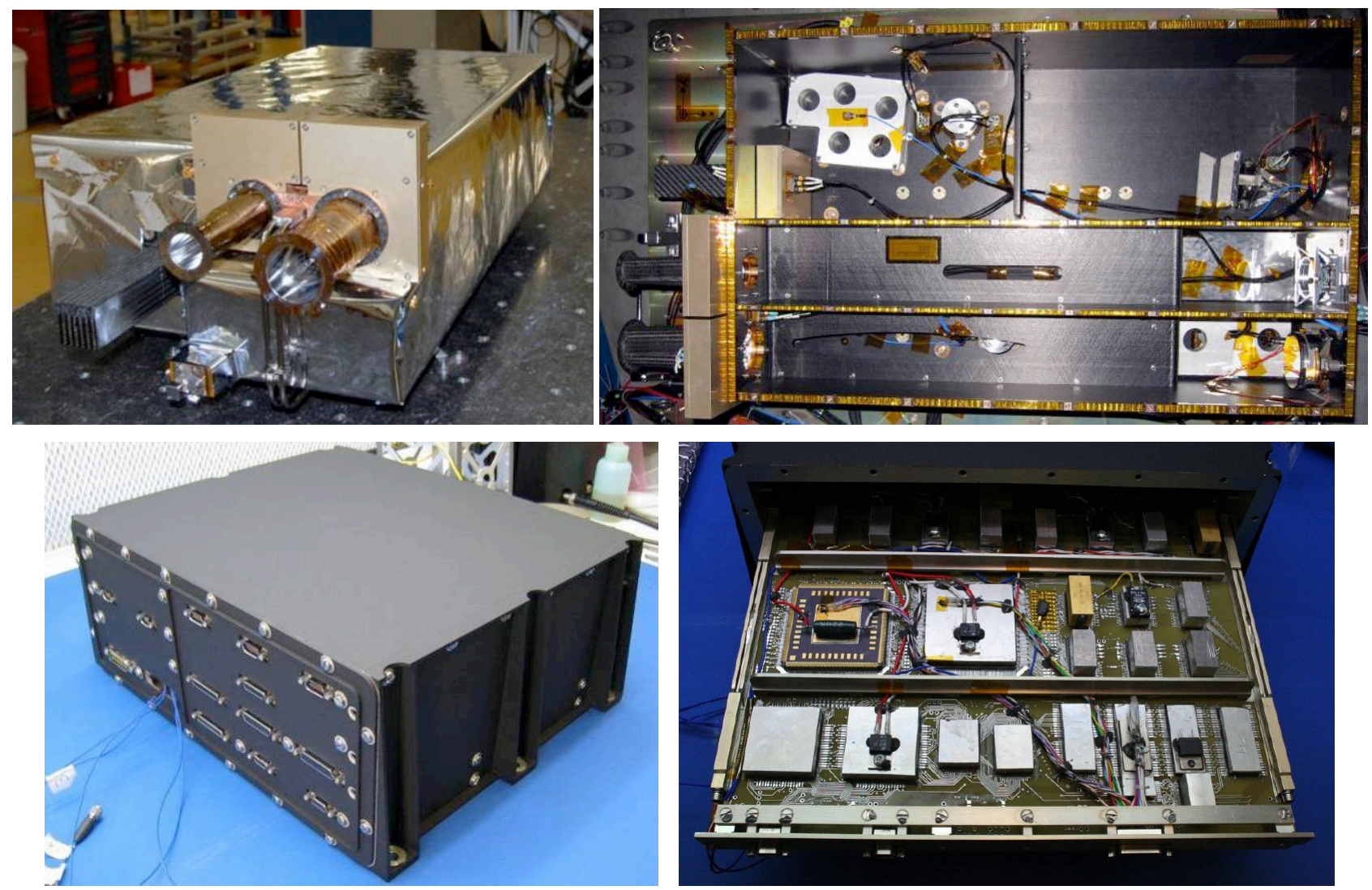

Figure 20 - EUI STM (top OBS unit; bottom: CEB unit)

\subsection{OBS STM thermal test}

A dedicated thermal test setup has been developed to perform the thermal balance test of the OBS STM unit (Figure 21).

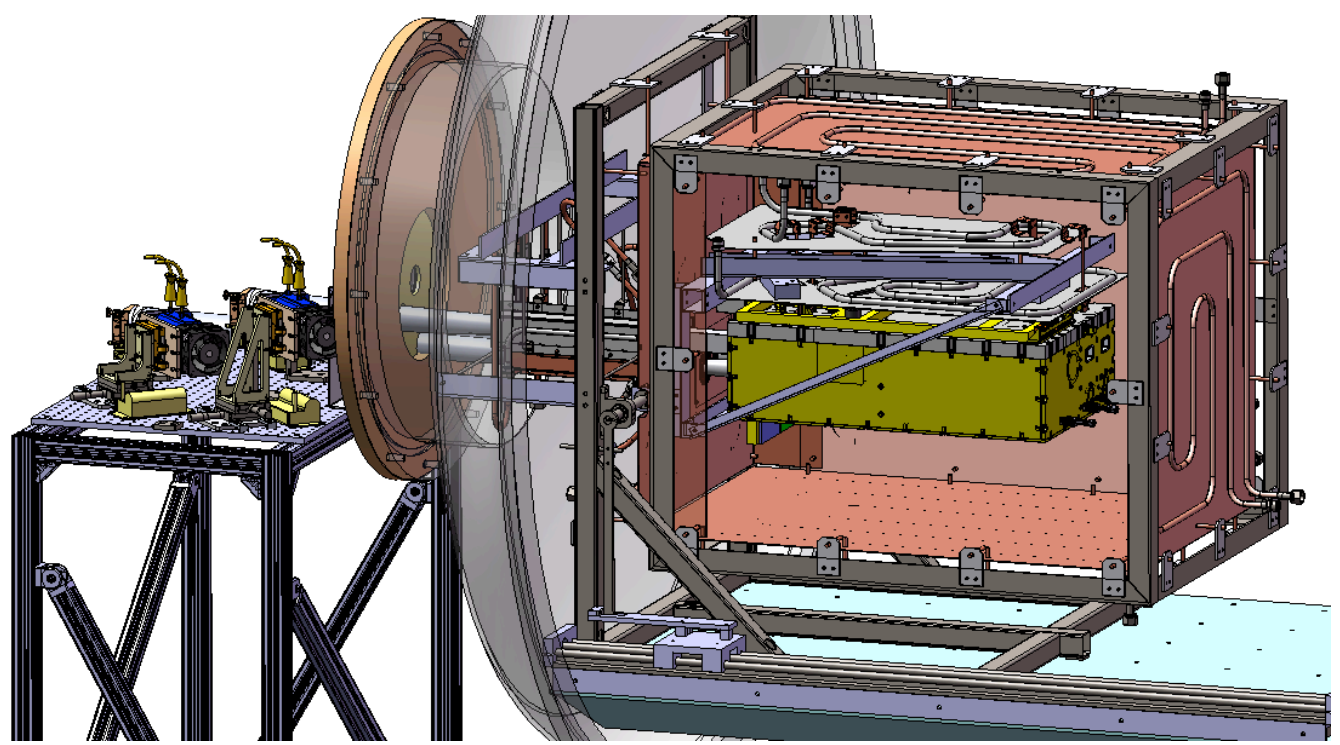

Figure 21 - EUI STM thermal balance test overview. The OBS unit is nested in $1 \mathrm{~m}^{3}$ thermal shroud, within a 2 meter vacuum chamber, mounted on a rotating mechanism, behind dummy spacecraft heat shield feedthroughs and facing a simulated solar heat flux. 
A dedicated illumination test system was provides 13 solar constants at the entrance baffle / entrances filters and simulate the effective solar heat input (Figure 22). The spacecraft heat shield feedthrough were also implemented by use of copper tubes heated to the expected temperature of $250^{\circ} \mathrm{C}$ to represent the infrared flux input from the spacecraft.

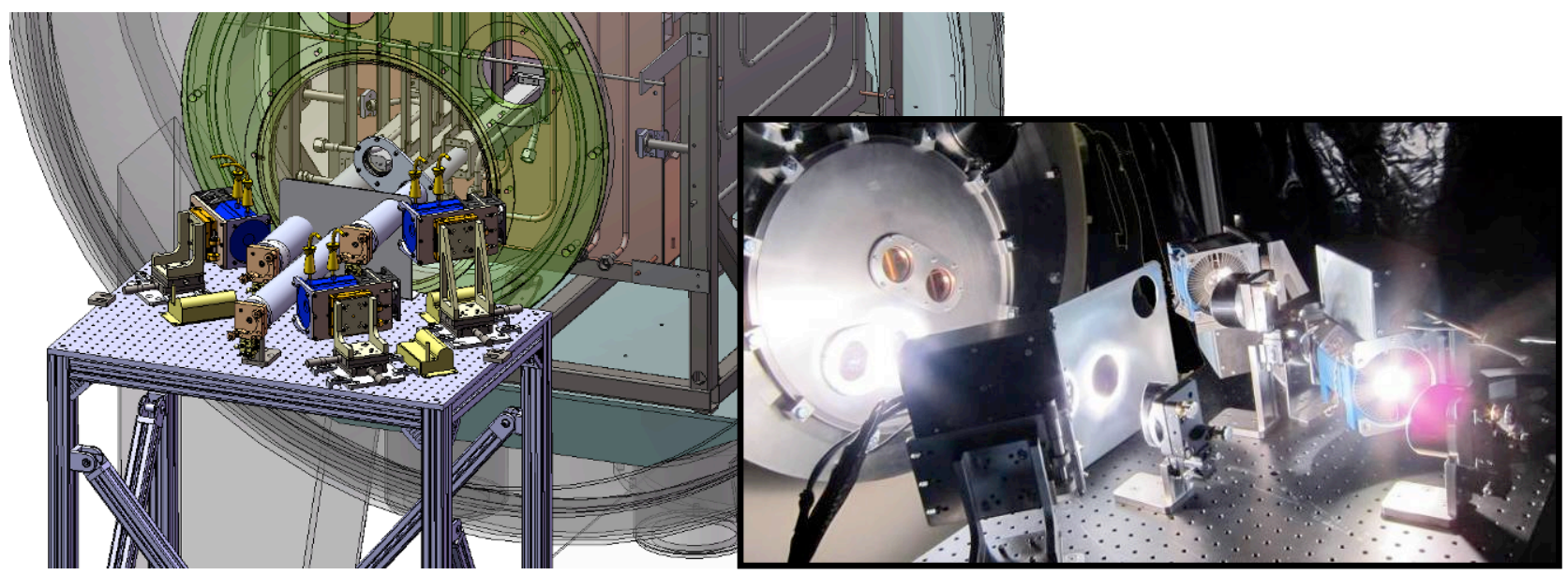

Figure 22 - EUI solar simulator test setup: one Xenon lamp $(750 \mathrm{~W})$ per channel is collimated with approximate Sun divergence

Internal heaters were operated to simulate the operational heat dissipation by electronic units (cameras detector and FEE, HVU, filter wheel).

The heat exchanges with the S/C environment were also properly modelled by use of regulated heaters connected to the unit $\mathrm{CE} / \mathrm{ME} / \mathrm{HE}$ thermal interfaces (Figure 23). The OBS STM unit was mounted upside-down to allow heat pipe operation even against gravity (i.e. evaporator below condenser).

The thermal mathematical model (TMM) of the asbuilt OBS STM unit has been implemented in the test environment and correlated for the hot and cold operational cases (Figure 24). It showed in particular that the heat pipe and associated thermal link properly evacuate the solar heat load and that the entrance filters highest temperature is below $200{ }^{\circ} \mathrm{C}$. It also allowed to measure the heat load from the spacecraft thermal interfaces to the spacecraft (CE, ME and HE) toward the OBS structure.

As part of the thermal test sequence, a qualitative measurement of the thermo-elastic deformation of the OBS unit has been performed. It showed that the HRI primary mirrors interfaces, located on the OBS back panel, are moving more than expected (20 arcsec per $10^{\circ} \mathrm{C}$ variation). An improvement of the back panel was, therefore, initiated to reduce such deviation that impacts the instrument channel co-alignment.

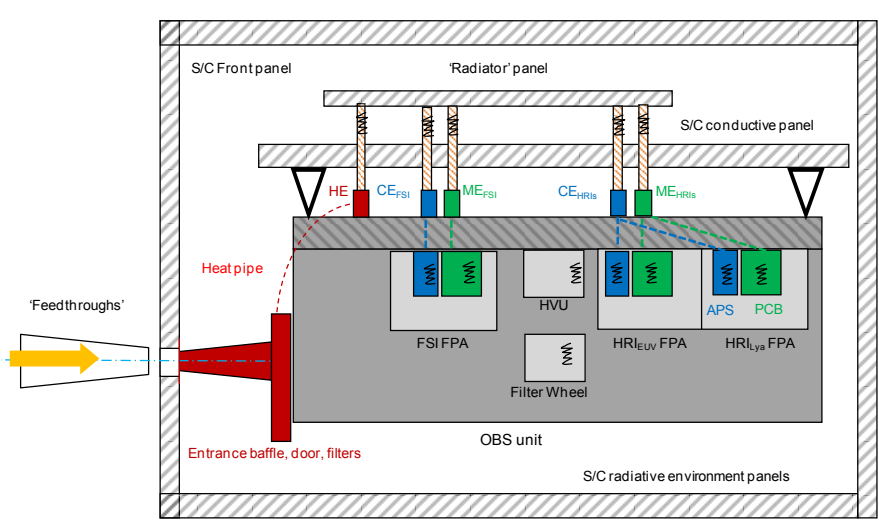

Figure 23 - EUI STM thermal balance test configuration

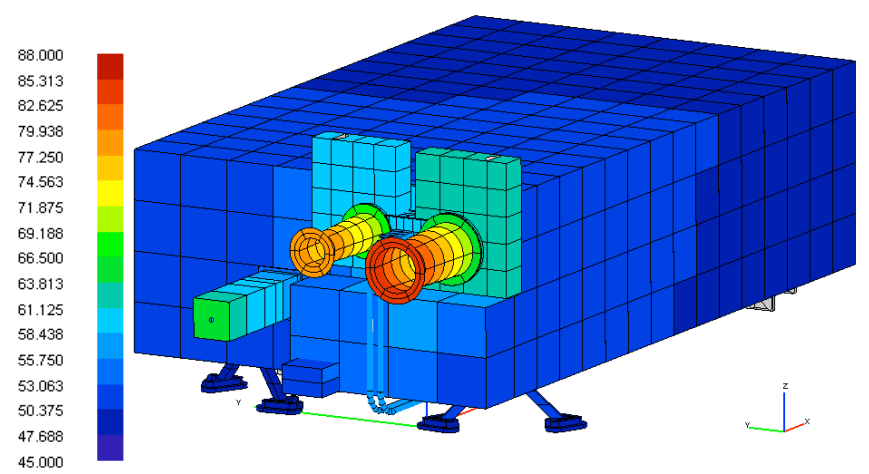

Figure 24 - EUI STM temperature map, in units of ${ }^{\circ} \mathrm{C}$, in-flight operational (door open) case, after correlation 


\subsection{OBS STM mechanical test}

The OBS STM unit was also submitted to mechanical vibration tests, including high sine and high random levels as per Table 8. The test was conducted on the Centre Spatial de Liège 4522LX shaker (Figure 25). For that test, force gauges have also been implemented to measure the force at the unit interface.
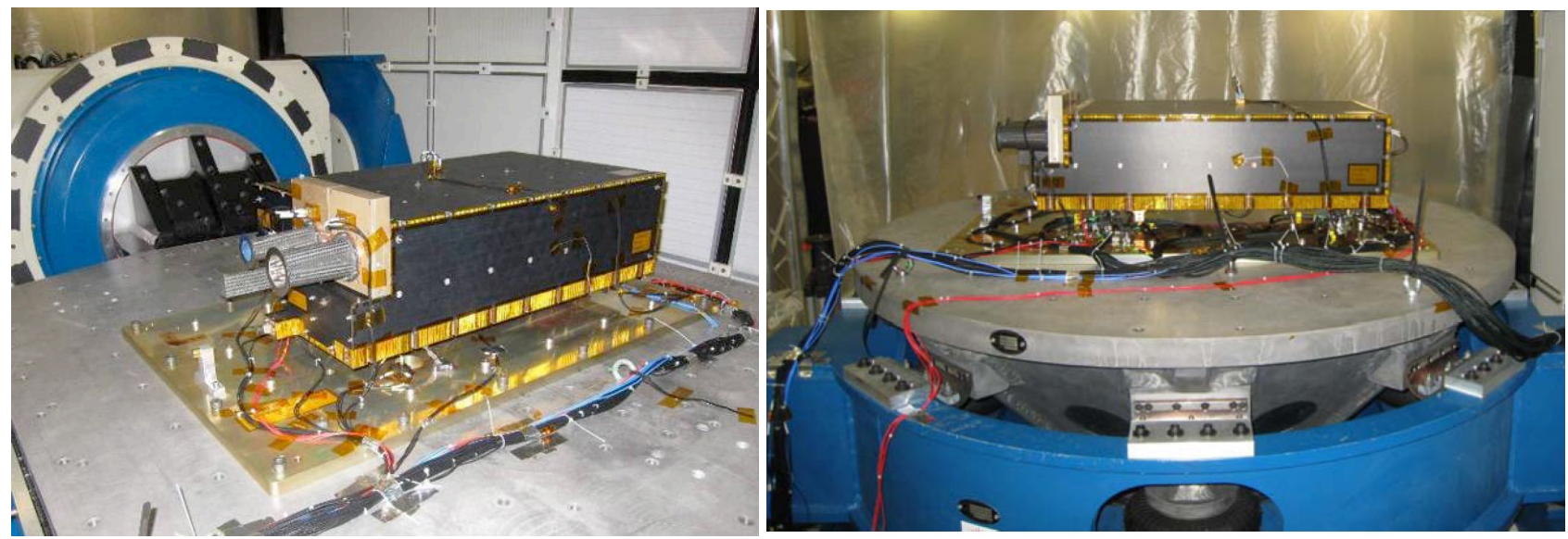

Figure 25 - EUI OBS STM on shaker for vibration (left: Y axis, right: Z axis)

The OBS unit has passed all the levels without any significant change in frequency or amplitude, proving its capability to withstand such very high loads. The OBS structure finite element model has also been correlated taking into account the measured signatures.

The center of gravity (CoG) and inertia have also been measured and compared with the predicted values, both showing only a few percent difference.

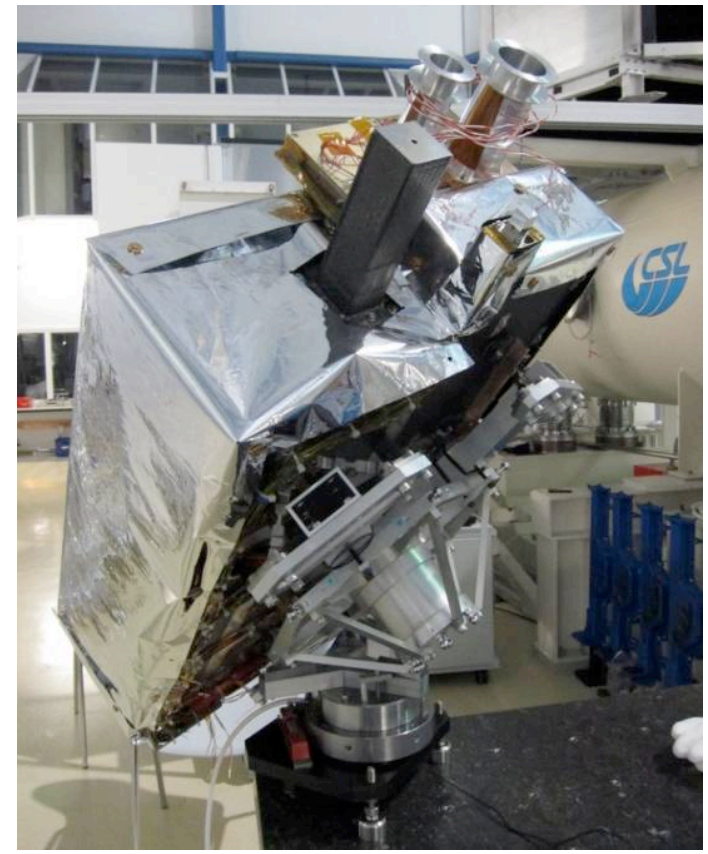

Figure $26-\mathrm{CoG}-$ Inertia Measurement
Table 8 - EUI sine and random loads

\begin{tabular}{|c|c|c|c|}
\hline Axis & Frequency $\mathbf{( H z )}$ & Qualification & Acceptance \\
\hline \multirow{2}{*}{ Out of plane } & $5-23$ & $11.3 \mathrm{~mm}$ & $9.9 \mathrm{~mm}$ \\
\cline { 2 - 4 } & $23-100$ & $24 \mathrm{~g}$ & $16 \mathrm{~g}$ \\
\hline \multirow{2}{*}{ In plane } & $5-20$ & $9.9 \mathrm{~mm}$ & $6.6 \mathrm{~mm}$ \\
\cline { 2 - 4 } & $20-100$ & $16 \mathrm{~g}$ & $10.7 \mathrm{~g}$ \\
\hline
\end{tabular}

\begin{tabular}{|c|c|c|}
\hline Axis & $\begin{array}{c}\text { Frequency } \\
{[\mathrm{Hz}]}\end{array}$ & Qualification \\
\hline \multirow{8}{*}{$\begin{array}{l}\text { Perpendicular } \\
\text { to mounting } \\
\text { plane ( } \mathrm{Z} \text { axis) }\end{array}$} & $20-80$ & $+6 \mathrm{~dB} / \mathrm{Oct}$ \\
\hline & $80-315$ & $0.16 \mathrm{~g}^{2} / \mathrm{Hz}$ \\
\hline & $315-365$ & $-29.68 \mathrm{~dB} / \mathrm{Oct}$ \\
\hline & $365-405$ & $0.035 \mathrm{~g}^{2} / \mathrm{Hz}$ \\
\hline & $405-425$ & $+41.72 \mathrm{~dB} / \mathrm{Oct}$ \\
\hline & $425-750$ & $0.07 \mathrm{~g}^{2} / \mathrm{Hz}$ \\
\hline & $750-2000$ & $-4 \mathrm{~dB} / \mathrm{Oct}$ \\
\hline & & $10.66 \mathrm{~g} \mathrm{rms}$ \\
\hline \multirow{10}{*}{$\begin{array}{l}\text { Parallel to } \\
\text { mounting } \\
\text { plane (X axis) }\end{array}$} & $20-80$ & $+4 \mathrm{~dB} / \mathrm{Oct}$ \\
\hline & $80-165$ & $0.1 \mathrm{~g}^{2} / \mathrm{Hz}$ \\
\hline & $165-185$ & $-77.42 \mathrm{~dB} / \mathrm{Oct}$ \\
\hline & $185-225$ & $0.004 \mathrm{~g}^{2} / \mathrm{Hz}$ \\
\hline & $225-250$ & $86.15 \mathrm{~dB} /$ Oct \\
\hline & $250-300$ & $0.1 \mathrm{~g}^{2} / \mathrm{Hz}$ \\
\hline & $300-400$ & $-6.26 \mathrm{~dB} / \mathrm{oct}$ \\
\hline & $400-1000$ & $0.055 \mathrm{~g}^{2} / \mathrm{Hz}$ \\
\hline & $1000-2000$ & $-3 \mathrm{~dB} /$ Oct \\
\hline & & $9.84 \mathrm{~g} \mathrm{rms}$ \\
\hline \multirow{10}{*}{$\begin{array}{l}\text { Parallel to } \\
\text { mounting } \\
\text { plane (Y axis) }\end{array}$} & $20-80$ & $+4 \mathrm{~dB} / \mathrm{Oct}$ \\
\hline & $80-220$ & $0.1 \mathrm{~g}^{2} / \mathrm{Hz}$ \\
\hline & $220-228$ & $-70.33 \mathrm{~dB} / \mathrm{Oct}$ \\
\hline & $228-252$ & $0.04 \mathrm{~g}^{2} / \mathrm{Hz}$ \\
\hline & $252-260$ & $81.36 \mathrm{~dB} /$ Oct \\
\hline & $260-300$ & $0.1 \mathrm{~g}^{2} / \mathrm{Hz}$ \\
\hline & $300-400$ & $-6.26 \mathrm{~dB} / \mathrm{oct}$ \\
\hline & $400-1000$ & $0.055 \mathrm{~g}^{2} / \mathrm{Hz}$ \\
\hline & $1000-2000$ & $-3 \mathrm{~dB} / \mathrm{Oct}$ \\
\hline & & $10.10 \mathrm{~g} \mathrm{rms}$ \\
\hline
\end{tabular}




\subsection{CEB STM thermal and mechanical test}

The CEB STM unit was also submitted to mechanical vibration tests (Figure 27), with similar levels as for the OBS unit. The first measured resonance frequency $(373 \mathrm{~Hz})$ is higher than predicted, but the STM mass was lower than in the finite element model. The maximum board response to random load was 118 gRMS (360 g, at 3 ) but very limited frequency shift was observed, and detailed visual inspections did not show any form of degradation or change in the structure.
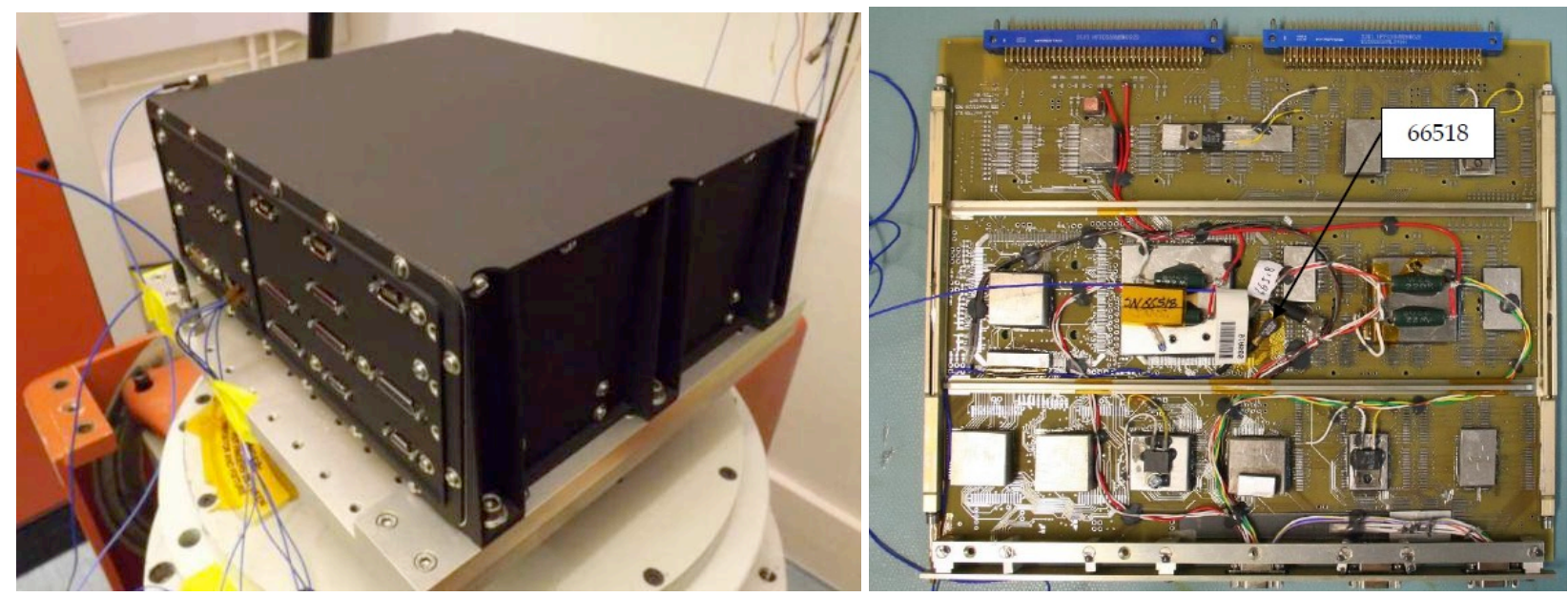

Figure 27 - EUI CEB STM (left: on shaker for vibration, right: PCB \#1 with dummy mass and accelerometer)

It was then followed by a thermal balance and vacuum test sequence (Figure 28). The thermal balance test allowed the correlation of the CEB thermal mathematical model. The thermal cycle allowed to validate the survival of representative electronic components (dummy parts) and of their soldering on dummy boards.
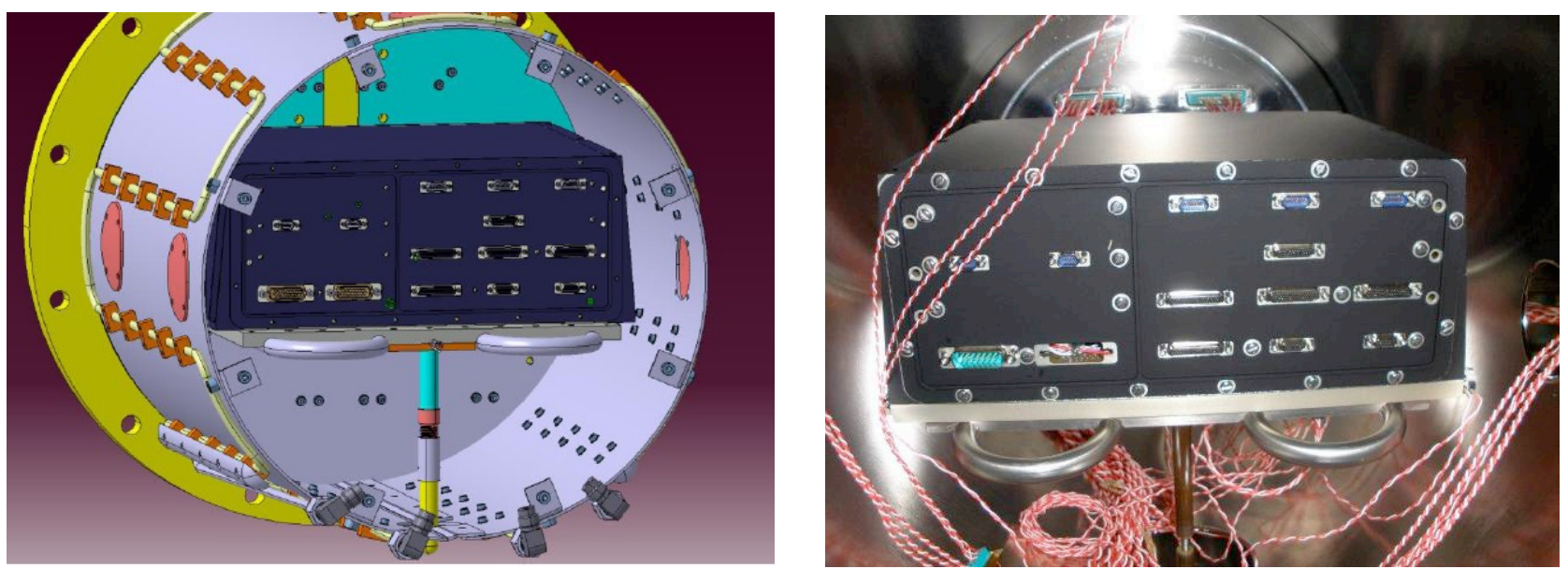

Figure 28 - EUI CEB STM (left: on shaker for vibration, right: in thermal shroud)

\section{ELECTRICAL AND QUALIFICATION MODELS}

\subsection{Electrical Model}

In parallel with the STM activities, an electrical model of the EUI instrument has been developed and manufactured. It is currently under validation before integration on the Solar Orbiter spacecraft Electrical Test Bench (ETB).

The ETB and delivered instrument EM units are intended to validate the electrical interfaces between the instruments and the spacecraft on-board computer (TM/TC protocols, functional interfaces, operational procedures) but also to perform conductive EMC tests (no radiative EMC will be performed on the ETB). 
The CEB EM unit will thus be flight representative (external housing and flight-like boards with lower grade electrical components) in order to fully validate the data and power interfaces with the spacecraft (Figure 29).

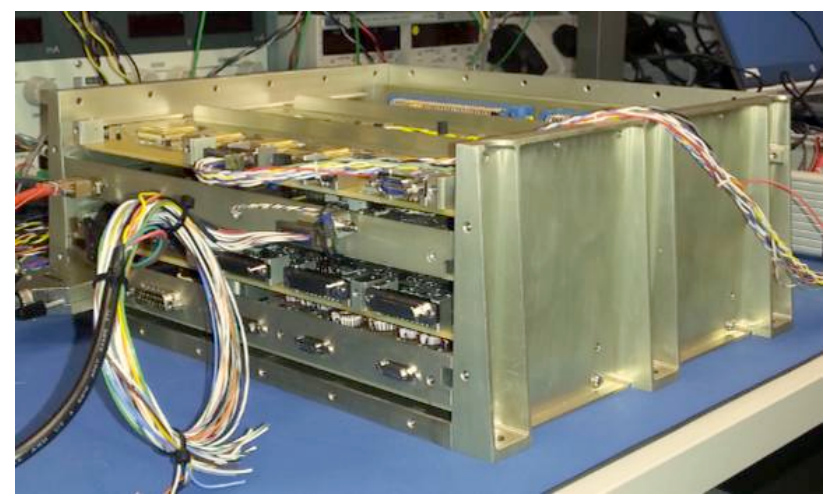

Figure 29 - EUI CEB EM unit (here open with all cards fitted and powered on-board converter on bottom card from a single $+28 \mathrm{~V}$ power supply)

The OBS EM will however be limited to an aluminium plate supporting some electrically representative sub-systems. It will contain one camera (not shape representative), one filter wheel motor drive system and a representative HVU box (Figure 30 ). The EM camera is based on the preliminary design architecture (Figure 31 ) and a 2k x 2k ISPHI detector.

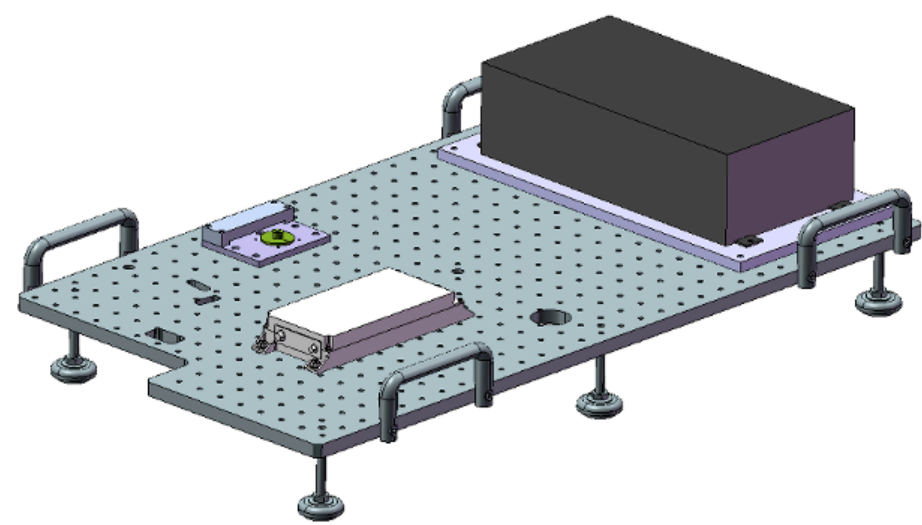

Figure 30 - EUI OBS EM unit

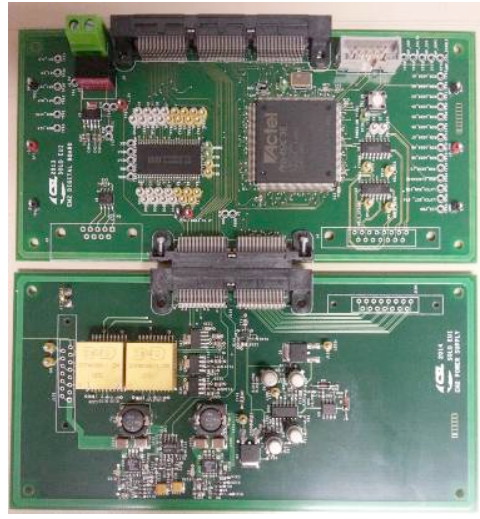

Figure 31 -FEE EM boards

\subsection{Qualification Model}

The Qualification Model (QM) is a full instrument, with the two OBS and CEB flight-like units, capable of supporting a full sequence of qualification testing. The objectives of the QM are the followings:

- Optical: verification of integration and alignment, end-to-end verification of optical paths,

- Electrical: verification of electrical performances, incl. EMC tests, validation of on-board software and functional interfaces,

- Mechanical: qualification at unit level,

- Thermal: qualification at unit level (the test setup developed for the OBS STM will be re-used),

- Performances: on-ground calibration preparation.

The QM manufacturing has been initiated on the basis of the CDR design, taking into account the lessons learned from the STM units, and using controlled drawings and necessary levels of PA and configuration control procedures.

The parts used for the OBS QM will not all be hi-rel./rad-hard but will be of the same type as the parts which shall be used for the flight hardware. The CEB EQM is however the flight spare and not refurbished, and is thus fully flight-like. 


\section{CONCLUSIONS}

The detailed design achieved for the instrument CDR releases the manufacturing of the qualification model and flight model sub-systems and parts. Some sub-systems design updates, derived from the STM tests, still however to be implemented to start the QM/FM parts manufacturing.

The QM will serve to qualify the instrument units and sub-units, in advance of the flight part assembly and acceptance tests. The flight model will then undergo a complete on-ground calibration that will serve as reference for in-flight operations, before integration on the Solar Orbiter Spacecraft.

In the meantime, the OBS STM and the OBS and CEB EM will be integrated on the respective STM and ETB spacecraft, and submitted to the respective test campaigns at spacecraft level. The results of these spacecraft activities, being too late for the instrument QM and FM development, will mainly be used as feedback for the QM and FM test activities.

\section{ACKNOWLEDGEMENTS}

The EUI instrument is developed in a collaboration which includes the Centre Spatial de Liège (Belgium), the Institut d'Astrophysique Spatiale and the Institut d'Optique (France), the UCL Mullard Space Science Laboratory (UK), the Max Planck Institute for Solar System Research (Germany), the Physikalisch-Meteorologisches Observatorium Davos (Switzerland), and the Royal Observatory of Belgium (Belgium).

The Belgian institutions are funded by Belgian Federal Science Policy Office (BELPSO); the French institutions by Centre National d'Etudes Spatiales (CNES); the UK institution by the UK Space Agency (UKSA); the German institution by Deutsche Zentrum für Luft- und Raumfahrt e.V. (DLR), and the Swiss institution by the Swiss Space Office (SSO).

\section{REFERENCES}

[1] Fleck B., Harrison R. A., Marsden R. G., Wimmer-Schweingruber R., "Summary of the Solar Orbiter payload working group activities, Telescopes and Instrumentation for Solar Astrophysics" Proc. SPIE 5171, 123-130, (2004).

[2] Marsden R.G., Marsch E. and the Solar Orbiter Science Definition Team, "Solar Orbiter Science Requirements Document" SCI-SH/2005/100/RGM, Issue 1 Revision 2 (2005).

[3] Mc Coy D., and the Solar Orbiter assessment team, "Solar Orbiter Payload Definition Document" SCI$\mathrm{A} / 2004 / 175 / \mathrm{AO}$, Issue 5 Revision 0 (2006).

[4] Auchere F., Song X., Rouesnel F., Appourchaux T., Fourmon J.-J., Le Clec'h J.-C., Berthe M., Defise J.-M., Mazy, E., Rochus P., Mercier R., Ravet M.-F., "Innovative designs for the imaging suite on Solar Orbiter, Solar Physics and Space Weather Instrumentation" Proc. SPIE 5901, 298-304, (2005).

[5] Vial J.-C., "Solar Orbiter: A unique opportunity for investigating small-scale physical processes at work in the magnetic solar atmosphere, Advances in Space Research" Advances in Space Research 36, 1375-1386 (2005).

[6] Young P. R., and the EUS Science Working Group, "Science With The Extreme Ultraviolet Spectrometer For Solar Orbiter" Proc. of The Second Solar Orbiter Workshop, 641 (2006).

[7] Rochus P., Halain J.P., Renotte E., Berghmans D., Zhukov A., Hochedez J.F., Appourchaux T., Auchère F., Harra L.K, Schühle U., Mercier R.., "The Extreme Ultraviolet Imager (EUI) on-board the Solar orbiter Mission" 60th International Astronautical Congress, (2009).

[8] Hochedez J.-F., Appourchaux T., Defise J.-M., Harra L. K., Schuehle U., Auchère F., Curdt W., Hancock B., Kretzschmar M., Lawrence G., Marsch E., Parenti S., Podladchikova E., Rochus P., Rodriguez L., Rouesnel F., Solanki S., Teriaca L., Van Driel L., Vial J.-C., Winter B., Zhukov A., "EUI, The Ultraviolet Imaging Telescopes of Solar Orbiter" The Second Solar Orbiter Workshop, (2006).

[9] Halain J.-P., Rochus P., Appourchaux T., Berghmans D., Harra L., Schühle U., Auchère F., Zhukov A., Renotte E., Defise J.-M., Rossi L., Fleury-Frenette K., Jacques L., Hochedez J.-F., Ben Moussa A., "The technical challenges of the Solar-Orbiter EUI instrument" Proc. SPIE 7732, 26 (2010) 
[10] Halain J.-P. , Berghmans D., Defise J.-M., Renotte E., Thibert T., Mazy E., Rochus P., Nicula B., De Groof A., Seaton D., Schühle U., "The First light of SWAP on-board PROBA2” Proc. SPIE 7732, 24 (2010)

[11] Auchère F., et al., "HECOR, a HElium CORonagraph aboard the Herschel sounding rocket" Proc. SPIE 6689, (2007)

[12] Schühle U., Halain J., Meining S., Teriaca L., "The Lyman-alpha telescope of the extreme ultraviolet imager on Solar Orbiter" Proc. SPIE Solar Physics and Space Weather Instrumentation IV, 8148, (2011)

[13] Halain J.-P., Rochus P., Renotte E., Appourchaux T., Berghmans D., Harra L., Schühle U., Schmutz W., Auchère, F., Zhukov A., Dumesnil C., Kennedy, T., Mercier R., Pfiffner D., Rossi L., Tandy J., Smith P., "The EUI instrument on board the Solar Orbiter mission: from breadboard and prototypes to instrument model validation" Proc. SPIE 8443, (2012)

[14]Delmotte F., et al., "Development of multilayer coatings for Solar Orbiter EUV imaging telescopes" Proc. SPIE $8877,(2013)$

[15]Fahmy S., Bagnasco G., Pacros A., Wirth K., "Solar Orbiter payload suite: a hotbed of innovation" 64th International Astronautical Congress, IAC-13-A3.5.2, (2013)

[16] Halain JP, Debaize A., Gillis JM., Jacques L., De Ridder T., Hermans L., Koch M., Meynant G., Schippers G., “The dual-gain $10 \mu \mathrm{m}$ back-thinned 3k x 3k CMOS-APS detector of the Solar Orbiter Extreme UV Imager" Proc. SPIE, 9144, (2014) 